\title{
The role of DNA-demethylating agents in cancer therapy
}

Parinaz Mehdipour ${ }^{\text {a }}$, Tracy Murphy ${ }^{a}$ and Daniel D. De Carvalho a,b,*

a. Princess Margaret Cancer Centre, University Health Network, Toronto, ON M5G 1L7, Canada

b. Department of Medical Biophysics, University of Toronto, Toronto, ON M5G 2M9, Canada

*Corresponding author:

Daniel D. De Carvalho: daniel.decarvalho@uhnresearch.ca

Mailing address: Princess Margaret Cancer Centre, University Health Network.

Office: Rm 9-309, Princess Margaret Cancer Research Tower,

101 College St. Toronto, M5G1L7

Phone number 1-416-581-7614 


\section{Abstract:}

DNA methylation patterns are frequently altered in cancer cells as compared to normal cells. A large body of research associates these DNA methylation aberrations with cancer initiation and progression. Moreover, cancer cells seem to depend upon these aberrant DNA methylation profiles to thrive. Finally, DNA methylation modifications are reversible, highlighting the potential to target the global methylation patterns for cancer therapy. In this review, we will discuss the scientific and clinical aspects of DNA methylation in cancer. We will review the limited success of targeting DNA methylation in the clinic, the associated clinical challenges, the impact of novel DNA methylation inhibitors and how combination therapies are improving patient outcomes.

\section{Key Words:}

DNA methylation,

Cancer,

DNA methyltransferase inhibitors,

Combination therapy,

Epigenetic therapy,

Novel DNMTi 


\section{Contents:}

1. Introduction

2. DNA Methyltransferases and demethylases

3. Role of DNA methylation during Development

4. DNA methylation aberrancies in cancer

5. DNA methyltransferase inhibitors in the clinic

6. Novel DNMTis

7. Combination therapy

8. Summary and perspective

Conflict of interest

Acknowledgments

References 


\section{Abbreviations:}

4mC, N4-methylcytosine;

5-aza-CdR, 5-aza-2'-dexoycytidine;

5-fC, 5-fluorocytosine;

5-FU, 5-Fluorouracil;

5AC,5-azacytidine;

5caC, 5-carboxylcytosine;

5hmC, 5-hydroxymethylcytosine;

5mC, C5-methylcytosine;

6mA, N6-methyladenine;

AML, Acute Myeloid Leukemia;

Bcl-2, B Cell Lymphoma-2;

BER, Base-Excision Repair;

CGI, CpG islands;

CLL, Chronic Lymphocytic Leukemia;

CMML, Chronic myelomonocytic leukemia;

CSCs, Cancer stem cells;

CTLA-4, Cytotoxic T-lymphocyte-associated protein-4;

DAC, 5-aza-2'-deoxycytidine; 
DKO, Double Knock-Out;

DNMTi, DNA Methyl Transferase inhibitor;

DNMTs, DNA Methyl Transferases;

DsRNA; Double-stranded RiboNucleic Acid;

ERVs, Endogenous Retroviruses;

ESCs, Embryonic Stem Cells;

FDA, Food and Drug Administration;

HDACis, Histone Deacetylase inhibitors;

HDACs, Histone Deacetylases;

HERV, Human Endogenous Retro Viruses;

HMAs, Hypomethylating Agents;

HSCs, Hematopoietic Stem Cells;

IDH1/2, Isocitrate Dehydrogenases 1 and 2;

IV, Intravenously;

KO, Knock-out;

LINEs, Long interspersed nuclear elements;

LSCs, Leukemic Stem Cells

LTRs, Long Terminal Repeats;

MBDs, Methyl-Binding Domain proteins;

MDS, Myelodysplastic Syndrome;

NSCLC, Non-Small Cell Lung Cancer; 
PARP, poly(ADP-ribose) polymers;

PARPi, poly(ADP-ribose) polymers inhibitor;

PCNA, Proliferating Cell Nuclear Antigen;

PD-1, Programmed cell death protein-1;

PRC, Polycomb Repressive Complex;

SC, Subcutaneously;

SINEs, Short Interspersed Nuclear Elements;

SSBs, Single-Strand Breaks;

TDG, Thymine DNA Glycosylase;

TET, Ten-eleven transcription;

TFs, Transcription Factors;

THU, Tetrahydrouridine;

TSG, Tumor Suppressor Gene;

UHRF1, Ubiquitin-like with PHD and Ring finger domains1; 


\section{Introduction}

Methylated bases exist in many species and includeC5-methylcytosine (5mC), N4methylcytosine $(4 \mathrm{mC})$ and N6-methyladenine $(6 \mathrm{~mA})$. The most common methylation mark inthe eukaryotic genome is $5 \mathrm{mC}$, which is mainly found in the context of $\mathrm{CpG}$ dinucleotides and is generally associated with heterochromatin formation and transcriptional repression. This isin contrast to prokaryotic DNA and bacterial DNA where the main methyl marks are $6 \mathrm{~mA}$ and $4 \mathrm{mC}$ respectively (Lyko, 2018). The process of adding a methyl group from S-adenosylmethionine intoC5 position of cytidine ring of DNA $(5 \mathrm{mC})$ is catalyzed by a familyof enzymes known as DNA Methyl-Transferases (DNMTs). 5mC isrecognized by Methyl-Binding Domain proteins (MBDs) includingMeCP2 and zinc finger proteins of the Kaiso family includingZBTB33, ZBTB4 and ZBTB38 (Bogdanovic \& Veenstra, 2009; Lewiset al., 1992). MBDs interact with other chromatin modifiers and transcription factors (TFs) that in turn result in regulation of gene expression (Clouaire \& Stancheva, 2008).

In mammalian genomes, not all $\mathrm{CpG}$ sites are methylated but the majority of methylated CpGs remain methylated during development, while CpG Islands (CGIs), which are CpGs found in CG dense regions, are constitutively hypomethylated (Smith \& Meissner, 2013). CGIs are located at the promoter of housekeeping genes or the genes which are involved in development and during tumorigenesis are frequently hypermethylated (Smith \& Pereira-Smith,1996). Orphan CGIs, constitute half of CGIs and are mainly found in intragenic or intergenic regions with a more dynamic methylation pattern and are methylated in early development (Sarda \& Hannenhalli, 2018; Smith \& Meissner, 2013). Furthermore, there are $\mathrm{CpG}$ dinucleotides known as $\mathrm{CpG}$ shores that exist between methylated $\mathrm{CpG}$ sites and unmethylated CGIs and have tissue-specific DNA methylation patterns (Irizarry et al., 2009). 
DNA structure that results from cytosine methylation affects the binding affinity of TFs. Systematic analysis has shown that while $\mathrm{CpG}$ methylation inhibits binding of a large portion of TFs including basic Helix-loop-helix, basic Leucine Zipper domain and E-twenty six, others prefer binding to methylated $\mathrm{CpGs}(\mathrm{mCpG})$. Most TFs with a preference for $\mathrm{mCpG}$ have developmental roles and include Homeodomain, POU and NEAT proteins (Yin et al., 2017). Moreover, there are computational tools that can be used for identification of TF binding sites including position weight matric and Cytomod software that allows the characterization of binding specificities of TFs to $5 \mathrm{mC}$ (Viner et al., 2016).

DNA methylation patterns are perturbed in many human cancers (Esteller, 2007; Rice, Hormaeche, \& Licht, 2007). In the past two decades different studies have shown that tumor cells have global hypomethylated genomes with hypermethylation at specific loci including the promoter region of certain tumor suppressor genes (TSGs). While in normal human genome the CpG rich islands are hypomethylated (Herman \& Baylin, 2003). Hypermethylated CGIs are associated with methylated and acetylated histone tails, and although that remains unclear which of these modifications are imposed earlier, all of them are involved in gene expression regulation (Cameron, Bachman, Myohanen, Herman, \& Baylin, 1999).

\section{DNA methyltransferases and demethylases}

The human genome encodes 5 DNA Methyltransferases: DNMT1, DNMT2, DNMT3A, DNMT3B and DNMT3L.

DNMT1, DNMT3A and DNMT3B are known as canonical 5mC DNMTs (Robertson, 2005). DNMT2 and DNMT3L have all of the conserved methyltransferase motifs but no in vivo 
catalytic activity has been described thus far and they are known as non-canonical DNMTs. Recently, DNMT4, DNMT5 and DNMT6 have been identified in algae and fungi (de Mendoza et al., 2018; Huff\& Zilberman, 2014; Lyko, 2018). Dnmt-knockout (KO) mice haverevealed that DNMTs are required for regulation of gene expres-sion in several developmental processes including embryogenesis, X-chromosome inactivation, genomic imprinting and silencing of repetitive elements (Goto \& Monk, 1998; Li, Beard, \& Jaenisch, 1993; Li, Bestor, \& Jaenisch, 1992; Schaefer, Ooi, Bestor, \& Bourc'his, 2007; Walsh, Chaillet, \& Bestor, 1998).

\section{DNMT1}

DNMT1 is the most abundant and the first discovered methyltransferase in somatic cells. It has higher preferences for hemi-methylated DNA, and is involved in generating symmetrically methylated CpGs during DNA replication, for this reason it is considered a maintenance methyltransferase (Jones \& Baylin, 2007; Portela \& Esteller, 2010; Smith \& Meissner, 2013)

(Fig. 1). During S-phase of the cell cycle, DNMT1 localizes to the replication fociand through its interaction with Proliferating Cell Nuclear Antigen (PCNA) and Ubiquitin-like with PHD and Ring finger domains1(UHRF1), generates symmetrically methylated CpG dinucleotides at hemimethylated DNA (Avvakumov et al., 2008; Sharif et al., 2007). UHRF1 is recruited to the replication forks through inter-action with hemimethylated DNA and to heterochromatin via interaction with H3K9me2/3marks. C-terminal RING domain of UHRF1 as an E3 ubiquitin ligase, results in ubiquitination of H3at lysine 18 and 23, then DNMT1, by recognizing these imposed ubiquitin marks localizes into replication forks and methylates the newly synthesized DNA strand (Li et al., 2018). It has been reported that depletion of UHRF1, which prompts global hypomethylation, is embryonically lethal (Sharif et al., 2007). 
To ensure a precise global DNA methylation, the activity of PCNA-UHRF1 and DNMT1 axis is regulated by a complex of chromatin modifier enzymes. DNMT1 activity is stabilized by histone deacetylase 1 (HDAC1) and presumably histone demethylases including LSD1 (Hosseini \& Minucci, 2017; Wang et al., 2009). In contrast, DNMT1 is destabilized by histone acetyl transferases such as TIP60 and SET7 histone methyltransferase, which trigger ubiquitination of the N-terminal domain of DNMT1 by the RING domain of UHRF1 and leads to proteosomal degradation of DNMT1 (Du et al.,2010; Wang et al., 2009).

The crucial role of DNMT1 in mammalian development has been discovered by generating the Dnmt1-null mice. Dnmt1-KO mice dis-played global 5mC reduction with delay in development and did not survive mid-gestation, highlighting the importance of Dnmt1during development ( $\mathbf{L i}$ et al., 1992). Generating mice with hypo-morphic Dnmt1 that expressed Dnmt1 $90 \%$ less than the wild-type level, resulted in hypomethylation throughout the genome leading to chromosomal instability and the development of an aggressive T-cell lymphoma (Gaudet et al., 2003). Furthermore, a point mutation in the catalytic domain of Dnmt1 led to embryonic developmental arrest, indicating the importance of DNA methyltransferase activity of DNMT1 (Takebayashi, Tamura, Matsuoka, \& Okano, 2007).

\section{DNMT3 family:}

The study which was conducted by Okano et al, in 1998 led to the first characterization of DNMT3 family including Dnmt3a andDnmt3b genes. This family of DNMTs mediate de novo deposition of $5 \mathrm{mC}$, which refers to establishing methylation marks. It seemsDNMT3 family has the equal preference for hemi-methylated and unmethylated DNA (Okano, Bell, Haber, \& Li, 1999) (Fig. 1). In addition to de novo DNA methylation, DNMT3A and DNMT3B may have a 
maintenance role which is implied by the addition of $5 \mathrm{mC}$ on DNA sequences which are missed by DNMT1 during replication (Jones \& Baylin, 2007).

Dnmt3a-KO mice are viable but they die almost 4 weeks afterbirth without changes in DNA methylation, highlighting its role in later developmental stages. In contrast, Dnmt3b-KO is embryonically lethal indicating its role in early development, with no dramatic change in DNA methylation. Dnmt3a and Dnmt3b double KO (Dnmt3a-3b DKO) mice have developmental defects similar to Dnmt1-KO mice. Dnmt3a-3b DKO, due to a decrease in methylation and an increase in hemi methylation, have more drastic phenotypes than Dnmt3a-KO or Dnmt3b-KO embryos, and this confirms the overlapping functions of these 2 genes (Okano, Xie, \& Li, 1998, 1999).

DNMT3A and 3B are recruited to specific regions of DNA by other chromatin modifier enzymes such as G9A that is a histone methyltransferase (Dong et al., 2008). One of the specific roles of DNMT3A is methylation of non-CpG sequences in embryonic stem cells (ESCs) while, DNMT3B is involved in DNA methylation maintenance in the centromeric minor satellite repeats that facilitate proper cell division (Liang \& Weisenberger, 2017; Okano et al.,1998, 1999). These specific roles explain the different developmental defects in Dnmt3a-KO mice compared to Dnmt3b-KO.

Figure 1. De novo and maintenance DNA methylation. De novo DNA methylation is imposed by DNMT3A/B and maintenance DNA methylation is mediate by DNMT1 during S-phase of cell cycle. During DNA replication DNMT1 binds to the old hemi-methylated DNA strand and generates symmetrically mCpG on newly synthesized DNA strand. 


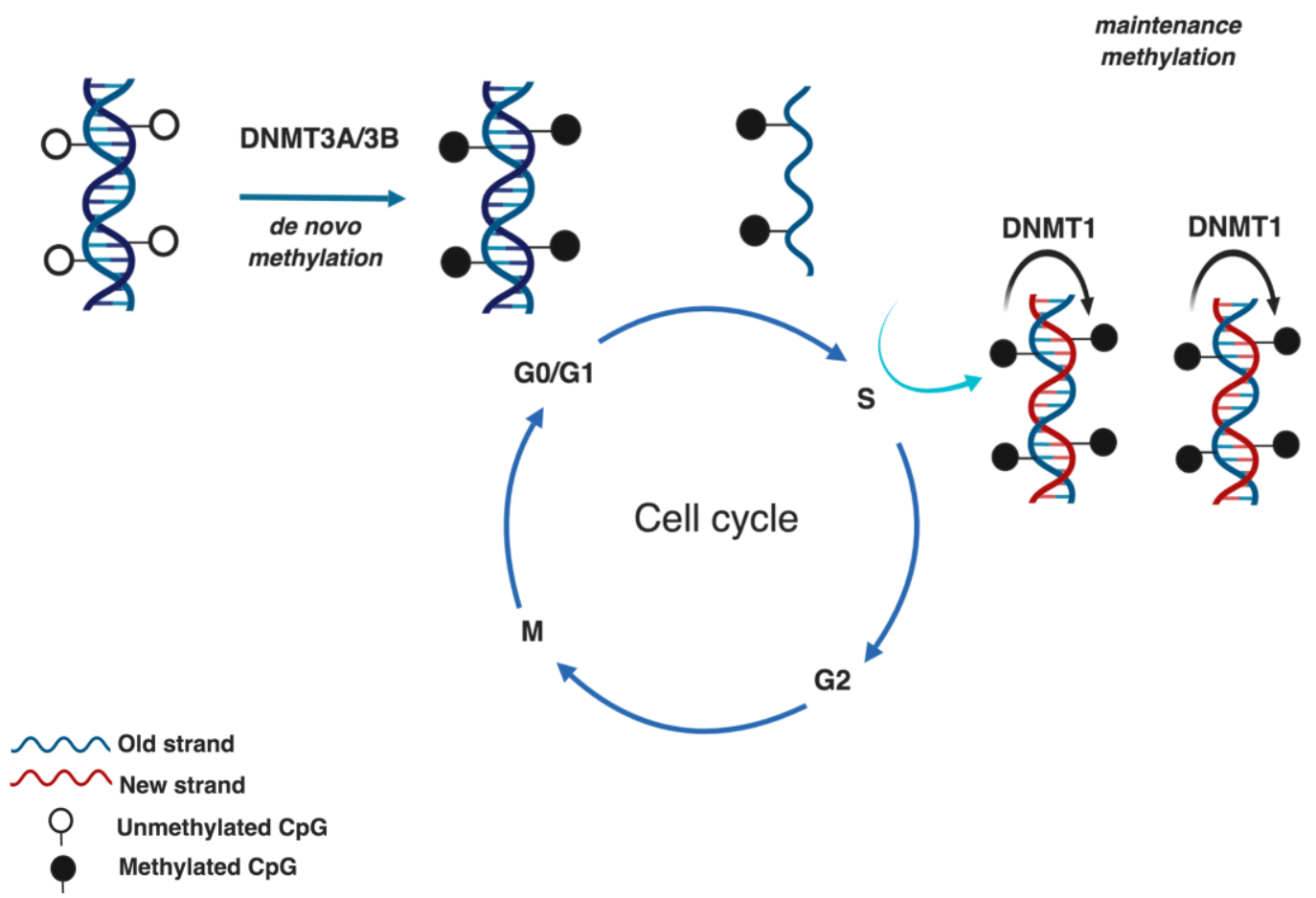

\section{DNMT3L:}

DNMT3L as a member of DNMT3 family is catalytically inactive, however through its cooperation with DNMT3A and 3B, is involved in regulation of DNA methylation (Long, Smiraglia, \&Campbell, 2017; Neri et al., 2013). It has been postulated that DNMT3L stimulates de novo methylation mediated by DNMT3Aand DNMT3B (Chedin, Lieber, \& Hsieh, 2002; Suetake, Shinozaki, Miyagawa, Takeshima, \& Tajima, 2004). DNMT3L binds to DNA andinteracts with DNMT3A resulting in conformational changes of theDNMT3A active site, and in turn accelerates binding of DNA and S-adenosyl-methionine to DNMT3A (Gowher, Liebert, Hermann, Xu, \& Jeltsch, 2005). 
In ESCs, DNMT3L maintains hypomethylation at the promoter of bivalent developmental genes (the genes with both active $\mathrm{H} 3 \mathrm{~K} 4 \mathrm{~m} 3$ and repressive $\mathrm{H} 3 \mathrm{~K} 27$ me3marks) through its interaction with PRC2complex and counteracts with DNMT3A and DNMT3B (Neri et al.,2013). ESCs are the pluripotent cells which give rise to all cell types in multicellular organisms (Boiani $\mathbb{\&}$ Scholer, 2005). DNMT3L, which is highly expressed in ESCs, has a dual role in DNA methylation of these cells, it acts as a positive regulator of methylation by increasing methylation at the gene bodies of housekeeping genes and it plays the role of negative regulator of DNA methylation by decreasing the methylation at the transcription start site of bivalent genes (Neri et al., 2013).

In mammals, polycomb repressive complex proteins (PRCs) including PRC1 and PRC2, repress the transcription of genes involved in development and maintain the pluripotency of ESCs in the early embryo. PRC1 plays its role through monoubiquitylation of histone $\mathrm{H} 2 \mathrm{~A}$ and $\mathrm{PRC} 2$ through methylation of $\mathrm{H} 3$ at lysine 27 (H3K27me2/3), leading to chromatin compaction (Margueron \& Reinberg, 2011). There is strong evidence that Ten-Eleven Transcription1 (TET1) is necessary for localizing PRC2 to the unmethylated genomic loci (H. Wu et al., 2011). Moreover, further evidence indicates that the DNA methylation state is involved in modulating the occupancy of PRCs (Aloia, Di Stefano, \& Di Croce, 2013). It has been shown that promoters with $\mathrm{H} 3 \mathrm{~K} 27$ me3 marks switch to DNA methylation in tumorigenesis concomitant with loss of their PRC2 marks, a process named 'epigenetic switch' (Gal-Yam et al., 2008; Mohn et al., 2008; Simmer et al., 2012). 


\section{TET Family:}

DNA demethylation can occur through an active or a passive mechanism. Active mechanism refers to an enzymatic process that mediates DNA demethylation by modifying or removing 5mC. In contrary, passive DNA demethylation refers to absence of a functional DNMT which results in dilution and loss of $5 \mathrm{mC}$ during DNA replication (Wu \& Zhang, 2010) (Fig. 2).

The opposite role of DNMTs is carried out by the TET family of genes. TETs are involved in an active mechanism of removal of methyl marks through oxidation of $5 \mathrm{mC}$ and then thymine DNA glycosylase (TDG)-base excision repair (Kohli \& Zhang,2013). The TET family in mammals consists of TET1, TET2 andTET3. This family of proteins have dioxygenase enzymatic activity, which converts $5 \mathrm{mC}$ into 5-hydroxymethylcytosine $(5 \mathrm{hmC})$, as well as 5-fluorocytosine (5-fC) and 5-carboxylcytosine $(5 \mathrm{caC})$ resulting in DNA demethylation (Ito et al., 2011). 5hmC regulates gene transcription by impacting on chromatin structure through the recruitment of 5hmC-binding proteins and removing of the MBD proteins (Tahiliani et al., 2009). Furthermore, $5 \mathrm{hmC}$ is deaminated with activation induced cytidine deaminase and con-verted to hydroxy uracil forms, mismatches with guanidine that is detected and removed by TDG-base excision repair (Dominguez \& Shaknovich, 2014).

Figure 2. Passive and Active DNA demethylation. A) Passive DNA demethylation is due to absence of a functional DNMT1 during replication, that could be a result of DNMTi incorporation into DNA and trapping of DNMT1. B) Active DNA demethylation can be due to TET enzyme activity that results in removing of $5 \mathrm{mC}$ from DNA. 
Passive and active DNA demethylation

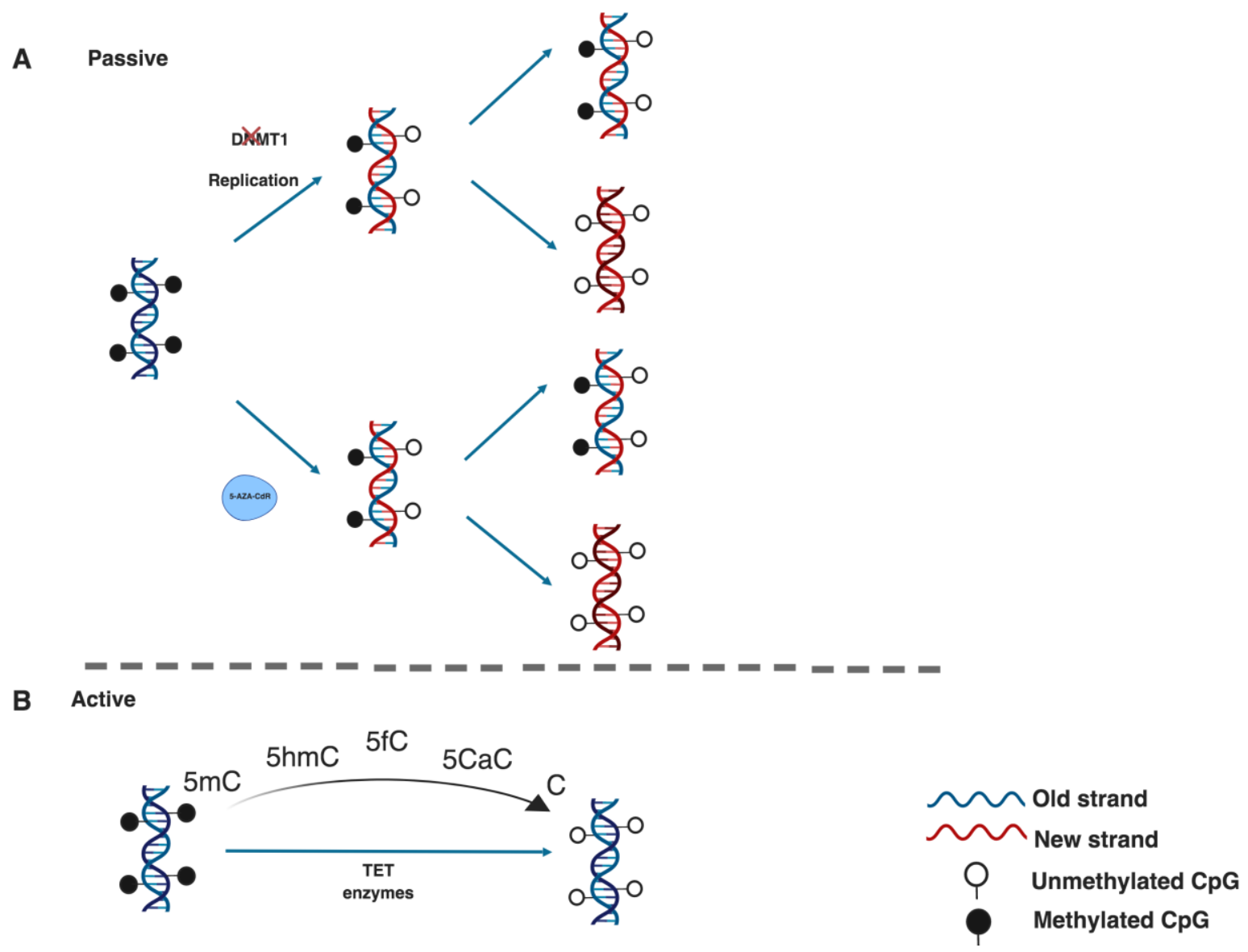

\section{Role of DNA methylation during Development:}

DNA methylation has a vital role in normal development. During mammalian development, transcriptional programming under-goes dynamic epigenetic changes including DNA methylation and two phases of global DNA demethylation. Phase I takes place after fertilization and phase II, during primordial germ cell migration. Prior to fertilization, paternal and maternal gametes are at different stages of their cell cycles. The maternal gamete is meiotically arrested and has a diploid genome while the paternal gamete has completed meiosis, which leads to a haploid genome. At the fertilization step when sperm penetrates the glycoprotein coat of oocyte, the egg undergoes the second meiosis, which results in a haploid gamete. In concert, deposition 
of histone H3.3 and DNA demethylation take place within a few hours post-fertilization in the zygote, and since this DNA demethylation occurs before the first cell division and is mediated by TET3, it is considered as an active demethylation. After zygote formation, the blastocyst formation from one-cell zygotes happens through loss of maternal DNA methylation by sequential cell divisions (Wu \& Zhang, 2010). The available evidence suggests that differentially methylated regions located at imprinting regions and a number of repetitive sequences (Birger, Shemer, Perk, \& Razin, 1999; Smallwood et al., 2011) may exhibit incomplete demethylation. At the time of implantation, the whole genome undergoes de novo methylation, and generates a bimodal pattern of DNA methylation. While most of the genome is methylated, some specific regions including repeat sequences in satellite DNA remain unmethylated. The methylation following implantation is cell-type specific or tissue-specific. One of the best known examples of methylation at this stage, is methylation of pluripotency genes which are known as Yamanaka genes, including OCT4 and NANOG in the embryo through differentiation (Cedar \& Bergman, 2012). The second wave of DNA demethylation occurs after implantation of blastocyst during primordial germ cells migration to the genital ridge through an active mechanism mediated by TET1 and TET2 (Kohli \& Zhang, 2013; Wu \& Zhang, 2010). This compensatory mechanism, which leads to inactivation of gene expression in one of the female $\mathrm{X}$-chromosomes throughout all the cells of the embryo post-implantation, is known as X-chromosome inactivation. X-chromosome inactivation balances the gene expression dosage between males (XY) and females (XX). A variety of epigenetic modifiers are involved in this phenomenon and DNMTs have a major role (Sharp et al., 2011).

In addition, genomic imprinting uses DNA methylation to establish monoallelic gene expression based on the parent of origin (Li et al., 1993; Peters, 2014). It has been described that genomic 
imprinting is mediated by DNMT3A and DNMT3L (Bourc'his, Xu, Lin, Bollman, \& Bestor, 2001; Kaneda et al., 2004). The in vivo experiments which were performed in murine models provide accumulating evidence that both paternal and maternal genomes are required for the normal embryogenesis (McGrath \& Solter, 1984). Furthermore, it has been reported that in some specific region of the genomes, the genes have distinct functions based on the parent of origin (Cattanach \& Kirk, 1985). Inheritance of these imprinted regions from only one of the parents results in certain genetic diseases, such as Prader-Willi Syndrome (Nicholls, Knoll,Butler, Karam, \& Lalande, 1989). The classical epigenetic modification that is assigned for conserving the imprinted regions is DNA methylation that acts in concordance with other epigenetic modifiers (Smith \& Meissner, 2013). At the late stages of gametogenesis, methyl marks can be erased from the imprinted genes and re-establish new parent-specific imprints (Shemer et al., 1996). Post-implantation the methylated imprints inherit through DNA replication by DNMT1 (Li et al., 1993).

\section{DNA methylation aberrancies in cancer:}

Altered DNA methylation acts as a hallmark of human cancers and two major methylation alterations have been identified (Jones \& Baylin, 2007). Global hypomethylation along the genome was the first reported epigenetic alteration in several human cancers including metastatic prostate cancer, chronic lymphocytic leukemia (CLL), hepatocellular carcinoma, and colon cancer (Bedford \& van Helden, 1987; Feinberg, Gehrke, Kuo, \& Ehrlich,1988; Gama-Sosa et al., 1983; Lin et al., 2001; Wahlfors et al., 1992). 
In addition to hypomethylation of satellite sequences and repetitive elements, focal hypermethylation of $\mathrm{CpG}$ islands in the promoter regions of TSGs and genes mediating cell growth or CGIs located in other genomic loci represents an important feature of DNA methylation aberrancies in cancer (Jones \& Laird,1999; Rodriguez et al., 2008; Wajed, Laird, \& DeMeester, 2001; Weisenberger et al., 2005; Widschwendter et al., 2004). Dysregulated expression of DNMTs has been elicited in a large spectrum of cancer types, including: breast cancer, hepatocellular carcinoma, renal cancer, gastric cancer, pancreatic cancer (Peng et al., 2006) and non-small cell lung carcinoma (NSCLC) (Agoston et al., 2005; Arai et al., 2006; Etoh et al., 2004; Kim et al., 2006; Peng et al., 2006; Saito et al., 2003).

Moreover, mutations in the genes encoding proteins that mediate DNA methylation including DNMT3A lead to an increase in DNA methylation. In addition, TET activity can be impaired by loss of function mutations in the genes encoding TET enzymes, which are often found in hematological malignancies (Langemeijer et al., 2009). TET2 mutations are among the most common mutations in myeloid malignancies and have a causative role in hematological malignancies initiation and progression and TET2 depletion leads to expansion of Hematopoietic Stem Cells (HSCs) and myeloid trans-formation (Chou et al., 2011; Quivoron et al., 2011; Timp \& Feinberg, 2013). Apart from mutations in the genes encoding the TET family, the TET enzymes activity can be altered by gain of function mutations in the isocitrate dehydrogenases 1 and 2 (IDH1/2) metabolic enzymes or loss of function mutations in succinate dehydrogenase and fumarate dehydratase. Mutations in the genes encoding these metabolic enzymes, respectively result in accumulation of 2-hydroxyglutarate, succinate and fumarate metabolites that inhibit TET enzymatic activity (Xiao et al., 2012; Xu et al., 2011). IDH1/2mutations impair hematopoietic differentiation through impairment of DNA demethylation by inhibiting TET 
enzymatic activity and contribute to leukemogenesis. Figueroa et al, reported that in acute myeloid leukemia (AML) patients that IDH1/2 and TET2mutations are mutually exclusive (Figueroa et al., 2010). Moreover, it has been shown that tumor hypoxia through oxygen shortage reduces the catalytic activity of TET enzymes (Thienpont et al., 2016). Decreased function of TET enzymes leads to hypermethylation of promoters of TSGs and contribute to tumorigenesis.

Moreover, DNA methylation within the target genes can increase the probability of mutational events, leading to chromosomal instability and production of a dysfunctional protein (Wajedet al., 2001). $\mathrm{CpG}$ Island methylator phenotype refers to high frequency of CGIs promoter methyltion, which divides some types of cancer, such as colorectal cancer and glioblastoma to distinct epigenetic subtypes. In colorectal cancer it has been demonstrated that the hypermethylation profile is associated with mutation of BRAF oncogene and in glioblastoma hypermethylation profile is correlated with gain of function mutations in IDH1, IDH2 or loss of function mutations in TET1 and TET2 (Hughes et al., 2013; Shen \& Laird, 2013).

In the tumors without any mutation in DNMT encoding genes or DNA demethylating genes, methylation can repress cell differentiation and result in tumorigenesis. Some controversy exists as to whether cancer cells arise from reprogramming of differentiated cells or they originate from differentiation block of stem cells. PCGs in ESCs are involved in repressing the genes, which are involved in development and differentiation (Bernstein et al., 2006). It has been demonstrated that the genes that are poised by PCGs are prone to CGI hypermethylation and silencing during tumorigenesis, suggesting a tumor driver role for methylation of PCG target genes (Ohm et al., 2007). An example of epigenetic perturbation that causes the differentiation block and 
oncogenesis is the methylation of CGIs associated with the genes mediating development, such as HOXA7 and HOXA9 (Rauch et al., 2007).

Moreover, intratumoral heterogeneity enables cancer cells to survive under evolutionary selection by having higher population diversity. In CLL, this heterogeneity does not only stem from genetic heterogeneity but is mediated by disrupted DNA methylation. This suggests that the stochastic events which result in variable DNA methylation between tumor cells may increase the epigenetic noise leading to the generation of a plastic evolutionary landscape for cancer cells (Landau et al., 2015; Meissner et al., 2008). In this regard, in the study which was done by Irizarry et al. it was shown that epigenetic alterations which generates the plastic evolutionary landscape in colorectal cancer mainly roots from DNA methylation changes in CpG shores rather than CGI. This epigenetic alteration increases the phenotypic variation of cancer cells and provides the variability that is required for tumorigenesis under selective conditions (Irizarry et al., 2009). Furthermore, it has been demonstrated that aberrant de novo DNA methylation in specific regions in cancer cells are essential for the cancer cells to thrive (De Carvalho et al., 2012).

These findings pave the way for the use of DNA methyltransferase inhibitors (DNMTi) in the clinic, aiming to target the genes of cancer cells that become addicted to methylation for their survival.

\section{DNA methyltransferase inhibitors in the clinic}

5-azacytidine (5AC, trade name; Vidaza ${ }^{\circledR}$, Azadine) and 5-aza-2'-deoxycytidine (5-aza-CdR;

DAC; also known as Decitabine, tradename; Dacogen $®)$ are two chemical nucleoside analogs of 
cytidine.5AC incorporates more into RNA (80-90\%) and less into DNA than its deoxyderivative DAC that incorporates into DNA only. Both of these chemotherapeutic agents were synthesized and used initially as cytotoxic agents in phase I and II clinical trials for treatment of myeloid malignancies (Von Hoff et al., 1979). During $S$ phase of the cell cycle these hypomethylating agents (HMAs) as the cytosine analogs incorporate into DNA, and through an irreversible covalent interaction they trap DNMTs (Shen \& Laird, 2012). The incorporation of nucleoside DNMTi into DNA can have several distinct effects: I) it can be mutagenic and predominantly induces mutations at the $\mathrm{CpG}$ dinucleotides, II) it can lead to heritable DNA demethylation through trapping of DNMT and inhibit the methylation mediated by enzymes during the following DNA replication, III) it can be cyto-toxic through excessive incorporation of cytosine analogs into DNA after thorough depletion of DNMTs (Jackson-Grusby, Laird, Magge,Moeller, \& Jaenisch, 1997; Juttermann, Li, \& Jaenisch, 1994; Shen \& Laird, 2012).

The mechanism of action of these DNMTis is concentration-dependent, at low concentrations they act as passive DNA HMAs by incorporating into DNA and trapping of DNMTs and sequentially mediating their proteosomal degradation, while at high doses they induce cytotoxicity through double-strand breaks, cell cycle arrest and inducing DNA damage (Gravina et al., 2010; Griffiths \& Gore, 2008). However, their demethylation potential is different and DAC has almost 90\% higher DNA demethylating potential compared to 5AC (Jones \& Taylor, 1980). Moreover, DAC induces apoptosis in a p53-dependant and $5 \mathrm{AC}$ in a p53-independent manner (Nieto et al., 2004). DAC is intracellularly activated from a monophosphate form to 5aza-2-deoxycytidine-triphosphate by deoxycytidine kinase and is integrated into DNA by DNA polymerase (Momparler, 2005).5AC is activated to a triphosphate form by a uridine-cytidine kinase and mainly incorporates into RNA, which leads to disruption of mRNA and protein 
synthesis (Aimiuwu et al., 2012) and to lesser extent into newly synthesized DNA (Aimiuwu et al., 2012; Lee, Karon, \& Momparler, 1974).

DNMTis seem to play their anti-tumor roles mostly through: I) Reactivation of TSGs and cancer testis antigens (CTAs). II) Repress-ing oncogenes by gene body demethylation. III) Activating viral mimicry and immune response. It is well-known that many TSGs are silenced by DNA hypermethylation in carcinogenesis, thus on eof the anti-tumor effects of DNMTi is through demethylation of CGIs in promoter and reactivation of the silenced TSGs (Baylin \&Jones, 2011). Moreover, hypomethylation of CTAs increases the immunogenicity of cancer cells, allowing their recognition and elimination by T-cells (Chou et al., 2012; James et al., 2013; Karpf,Bai, James, Mohler, \& Wilson, 2009; Siebenkas et al., 2017). Pharmacological DNA demethylation also induces the expression of transposable elements including human endogenous retroviruses (HERVs). In preclinical studies conducted in ovarian cancer and colorectal cancer cells, low dose of DAC demethylated ERVs, which in turn induced doublestranded RNA (dsRNA) and activated viral mimicry. Viral mimicry refers to a state in which activation of viral defense genes leads to an innate immune response against the cancer cells (Chiappinelli et al., 2015; Jones, Ohtani, Chakravarthy, \& De Carvalho, 2019; Roulois et al., 2015). Another anti-tumor role of DNMTi is played through silencing of oncogenes. It is interesting to note that in contrast to promoter methylation, gene body methylation is frequently associated with high gene expression. Yang et al. showed that low dose DAC could target gene body methylation, leading to downregulation of oncogenes such as c-MYC pathway (Yang et al., 2014) (Fig. 3).

Clinically, 5AC and DAC are administered subcutaneously (SC)and intravenously (IV) respectively as they have poor oral bioavailability. The mutual pathway for metabolism and 
elimination of these HMAs is deamination by cytidine deaminase which exists in the liver, and whole blood (Derissen, Beijnen, \& Schellens,2013). Both 5AC and DAC were FDA approved for the treatment of myelodysplastic syndrome (MDS) in 2004 and 2006 respectively (DeZern, 2015; Griffiths \& Gore, 2008; Gros et al., 2012; Kaminskas, Farrell, Wang, Sridhara, \& Pazdur, 2005). Two large phase three trials were pivotal in the FDA and European medicines agency (EMA) approval for 5AC in the treatment of MDS. An initial randomized clinical trial performed in the US by Silverman et al, was conducted in patients with high risk MDS. This trial clearly demonstrated that $5 \mathrm{AC}$ had a superior overall response rate of $60 \%$ compared to $5 \%$ in the best supportive care arm. More importantly it demonstrated that 5AC delayed the progression to AML (Silverman et al., 2002). A second larger international study of 358 high risk MDS patients,AZA-001, again in a randomized trial, further demonstrated that long term survival was doubled in high risk MDS patients treated with 5AC compared to available therapies (Fenaux et al., 2009).

Both of these trials used the French-American-Classification (FAB) classification of MDS, which included those patients with up $30 \%$, blasts in their marrow. When acute myeloid leukemia (AML) was reclassified in 2002 and defined as those patients with a blast percentage greater than $20 \%$ blasts, this allowed the use of $5 \mathrm{AC}$ in those patients with a blast percentage between 20-30\% (Vardiman, Harris, \& Brunning, 2002). In AML patients unfit for intensive chemotherapy 5AC has demonstrated proved efficacy, though predicting those patients who till gain most benefit continues to be challenging (Schuh et al., 2017). In 2007, 5AC was approved for the treatment of AML by the EMA.

DAC has also been approved internationally for the treatment of MDS. An initial randomized phase III study compared DAC with best supportive care and treatment was administered IV 
with the dose of $15 \mathrm{mg} / \mathrm{m}^{2}$ over $3 \mathrm{~h}$, every $8 \mathrm{~h}$ for 3 days every 6 weeks in 170 high risk MDS patients. This trial completed with $17 \%$ overall response rate, $9 \%$ complete response (CR), $8 \%$ partial response and $13 \%$ hematological response (Griffiths \& Gore, 2008). In comparison to 5AC, DAC did not delay progression to AML. Given that DAC had to be administered as an inpatient, a second international study permit-ting outpatient administration with an alternate dosing schedule was conducted. This study administered DAC at a dose of $20 \mathrm{mg} / \mathrm{m}^{2}$, by IV infusion daily for 5 days (Steensma et al., 2009). Response rate were comparable to the previous study and this regimen has been approved by the FDA.

Figure 3. Anti-tumor effects of DNMTis. DNMTis through A) Demethylation of Promoters activate Tumor suppressor genes, Differentiation, Repetitive elements and Cancer testis antigens, respectively induce Cancer cell death, differentiation, viral mimicry and immunogenicity. B) Demethylation of Gene bodies represses oncogenes resulting in cancer cell death.

Anti-tumor effects of DNA Hypomethylating Agents

A
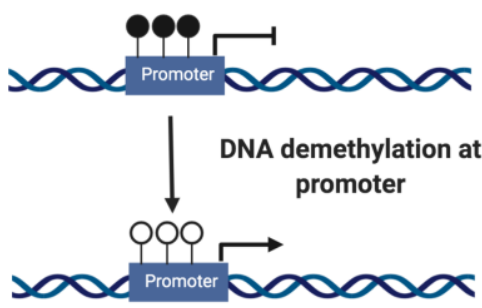

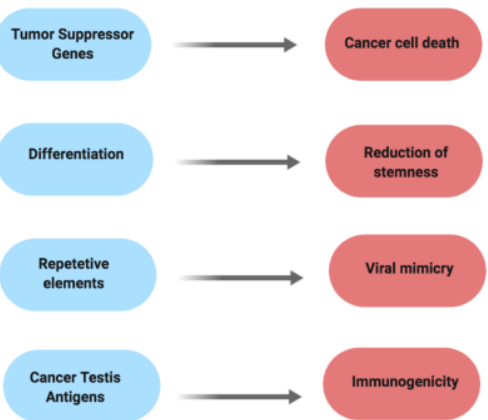

Antigens

B
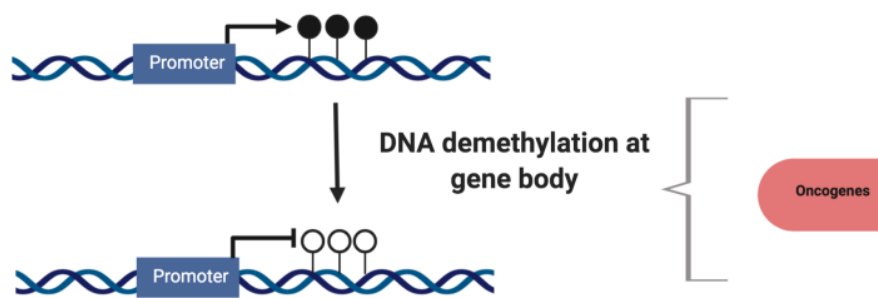

Cancer cell death 


\section{Clinical challenges:}

DNA incorporating features of nucleoside DNMTis during cell cycle is advantageous for targeting the transformed cells which are rapidly dividing, however not beneficial for treatment of diseases which do not have this characteristic. The other disadvantage is that the effect of currently available DNMTis is temporary and after DNTMi withdrawal the DNA methylation levels return to basal level (Kelly, De Carvalho, \& Jones, 2010). SC and IV administration of5AC and DAC respectively, is another challenge for clinical use of these HMAs. These methods of administration result in injection-site reaction, limit low-dose schedules and make it more difficult for patients to commute to hospital to get SC and/or IV administration (Cogle, Scott, Boyd, \& Garcia-Manero, 2015). And while there are ongoing clinical trials in the development of orally bioavailable5AC, it has yet not been given FDA approval. In solid tumors, the instability of HMAs, short-half life and lack of clinical response has hampered their use in clinical practice.

The effects of DAC on global hypomethylation was assessed inpatients with AML and acute lymphoblastic leukemia in early trials in the 1980s in which patients were treated with DAC (1 $\mathrm{mg} / \mathrm{kg} / \mathrm{h}$ ), and further analyses showed that DAC treatment had approximately 70\% DNA methylation inhibitory effect on the leukemic cells (Momparler, Bouchard, Onetto, \& Rivard, 1984). Recently, the inhibition of DNA methylation by DAC has been studied in vivo in leukemias in more detail (Issa, 2012; Malik \& Cashen, 2014). Although 5AC showed a survival benefit in high risk MDS patients, objective clinical response were observed in less than half of the patients on study and the main reason for treatment discontinuation continues to be relapse or progression to AML (Fenauxet al., 2009). In another study, the efficacy of DAC was tested in newly diagnosed older patients with AML and patients older than18-years-old with relapsed or 
refractory disease. DAC treatment resulted in $40.4 \%$ and $15.7 \%$ CR rate in both groups of patients, respectively (Ritchie et al., 2013).

IV administration of DAC shows an excellent distribution in the body fluids and elimination through metabolic processes (Jabbour, Issa, Garcia-Manero, \& Kantarjian, 2008). In the study conducted by van Groeningen et al., DAC was used in 21 patients with advanced solid tumors, and side effects included myelosuppression, mild and reversible increase of serum creatinine, nausea and transient fatigue (van Groeningen, Leyva, O'Brien, Gall, \& Pinedo, 1986). Due to the deamination with cytidine deaminase the plasma half-life of DAC in humans is short (Rivard et al., 1981). In a combination therapy, administration of tetrahydrouridine (THU) as the competitive inhibitor of cytidine deaminase before treatment with DAC, increased the absorption of DAC and reduced its cytotoxicity (Lavelle et al., 2012). Thus, THU can decrease the pharmacologic limitations of oral DAC. In Table 1, the features of 5AC, DAC and Oral Azacytidine with their recommended starting dose and schedules for clinical use is summarized (Cogle et al., 2015; Derissenet al., 2013) Approved labeling dacogen (decitabine) for injection. Available at http://www.accessdata.fda.gov).

Two other cytidine analogues which act as potential DNMTis through incorporation into DNA are 4-thio-2-deoxycytidineor TdCyd and 5aza-4-thio-2-deoxycytidine or aza-T-dCyd (Thottassery et al., 2014). These two potential DNMTi are currently in phase I clinical trials in patients with advanced solid tumors (https://clinicaltrials.gov/ct2/show/NCT02423057; https://clinicaltrials.gov/ct2/show/NCT03366116).

In summary, cell-cycle dependency, short half-life, continual administration through IV and SC injections, lack of efficacy and requirement of higher concentration of DNMTi that could 
potentially lead to drug toxicity in normal tissues limit the use of 5AC and DAC in patients with solid tumor malignancies.

\section{Novel DNMTis}

\section{Non-nucleoside DNMTi}

Recently, a few non-nucleoside DNMT inhibitors have been identified. Non-nucleoside DNMTis such as curcumin, procaine, hydralazine, epigallocatechin gallate, RG-108, 3-nitro-2-(3nitrophenyl) flavone and isoxazoline bind directly to the catalytic region of DNMTs without incorporation into DNA, forthis reason their cytotoxicity is less than nucleoside DNMTis. However, these DNMTis have low potency and low selectivity for DNMTs (Nebbioso, Carafa, Benedetti, \& Altucci, 2012). Valente and colleagues have identified a non-nucleoside DNMTi, named Compound 5 that was developed by chemical modification of SGI-1027, which is a quinolone-based anti-cancer drug. Compound 5displayed potent anti-proliferative effects against histiocytic lymphoma, breast cancer, Burkitt's lymphoma and prostate cancer at micromolar doses and indeed it was the first non-nucleoside DNMTi that has been tested in cancer cell lines (

Gros et al., 2015). Until now, none of these inhibitors has been used in clinical trials and their clinical safety and efficacy still needs to be examined.

\section{Guadecitabine (SGI-110)}

It has a longer half-life than its active metabolite DAC. A phase II clinical trial recommended 60 $\mathrm{mg} / \mathrm{m}^{2}$ in a 5-day schedule as the effective regimen for Guadecitabine in patients with treatmentnaïve AML which are not eligible for intensive chemotherapy (Kantarjian et al., 2017), but it failed to improve complete response and overall survival in a phase III trial in this patient population (NCT02348489) https://clinicaltrials.gov, however, the Phase III clinical trial for 
assessing the effect of Guadecitabine in leukemia patients with relapsed or refractory AML( NCT02920008) and the one in MDS or chronic myelomonocytic leukemia (CMML) patients who failed or relapsed after treatment with 5AC or DAC or both is still ongoing (NCT02907359).

\section{Selective and non-covalent inhibitors of DNMT1}

In a high-throughput screen a series of reversible, non-DNA incorporating inhibitors of DNA methyltransferases have been identified. These small molecule inhibitors are highly selective for DNMT1 over other DNMTs, which results in reduced global DNA methylation and reexpression of transcriptionally silenced genes in cancer cells. Since these inhibitors do not incorporate into DNA and do not induce DNA damages, they may provide benefits for clinical trials with a higher doses range and less toxicity (Pappalardiet al., 2018).

\section{Oral formulation of azacytidine (CC-486)}

CC-486 is the oral form of azacytine developed by Celgene that is in clinical development for treatment of hematological malignancies. The study, which was done by Savona et al, showed thatCC-486 administration (300 mg/day) in 14 days or 21 days per 28-day cycle was well tolerated with overall response of $48 \%$ in AML patients with median age of 68 years. Interestingly, patients who previously received IV or SC form of HMA had better hematological responses to CC-486 (Savona et al., 2015). Oral administration of AZA would be more convenient and less invasive for patients rather than subcutaneous injection, and it allows for alternative dosing and timeline. 


\section{Combination therapy}

The ongoing large number of clinical trials using DNMTis as monotherapy or in combination with other compounds emphasize the efforts of the oncological community to understand the unmet potential of these compounds in the clinic. Effective combination regimens will ideally simultaneously increase efficacy without increasing toxiticity. The rationale behind epigenetic combination therapy or epidrugs combo treatment is that there are different regulators of chromatin conformation, which contribute to aberrant gene transcription and lead to dysregulated cell growth resulting in cancer development. To this end, a growing body of evidences have shown that DNMTis can be used in combination with other epidrugs in various malignancies.

\section{DNMTi and Bcl-2 inhibitor:}

B-Cell lymphoma 2 (Bcl-2) family members have a crucial role in preventing apoptosis as prosurvival proteins through regulation of mitochondria outer membrane (Shamas-Din, Kale, Leber, \& Andrews, 2013). In AML, BCL-2 is overexpressed in leukemic stem cell (LSC) subpopulations suggesting targeting of BCL-2 in treatment of hematological malignancies may be effective (Lagadinou et al., 2013). Venetoclax or ABT-199 is a selective oral inhibitor of Bcl-2, which received FDA approval for treatment of CLL and small lymphocytic lymphoma in 2018 (https://clinicaltrials.gov/ct2/show/NCT02005471). BCL-2 inhibitors sensitize the myeloid malignancies to hypomethylating agents (Bogenberger et al., 2014), and the study, which was done by Jones et al., demonstrated in AML patients, combination of 5AC and Venetoclax blocks amino acid metabolism which is crucial for LSC survival and this is one of the mechanisms that 
provides rationale for Venetoclax and HMA combination regimen (Jones et al., 2018). As a result of a successful phase II trial in AML patients, Venetoclax in combination with DNMTi or low dose cytarabine, has received FDA approval for the treatment of AML patients unfit for intensive therapy (https://clinicaltrials.gov/ct2/show/NCT02203773; https://clinicaltrials.gov/ct2/show/NCT02287233). There are ongoing clinical trials that dissect the combination of these two agents in patients with hematological malignancies. In a phase III randomized, double blinded study with around 400 AML patients=> 18-year-old which were not treated before and are ineligible for standard induction therapy, the participants were received Venetoclax $400 \mathrm{mg}$ orally every day on Days $1-28$, plus $5 \mathrm{AC} 75 \mathrm{mg} / \mathrm{m}^{2}$ subcutaneously or intravenously once a day on cycle days 1 - 7 (28-day cycle). (https://clinicaltrials.gov/ct2/show/NCT02993523).

\section{DNMTis and HDACis:}

The rationale for the combination of DNMTi and HDACis is that DNA methylation and histone deacetylation are the two key epigenetic modifications contributing to gene silencing. Thus, for re-expression of the silenced genes, DNMTs and HDACs arose as key targets in the therapeutic arena. The mammalian genome is composed of 18 HDACs that are categorized into 4 classes, and this classification is based on their enzymatic activity and their homology to the yeast HDACs. With the exception of group III which is a NAD ${ }^{+}$-dependnt enzyme the 3 other classes are $\mathrm{Zn}^{2+}$-dependant enzymes (Hosseini \& Minucci, 2018; Mottamal, Zheng, Huang, \& Wang, 2015). Currently, the main challenge for clinical use of HDACis is that most of the available formulations are pan-HDAC inhibitors, while HDAC isoforms from the same family play distinct roles in different type of malignacies and even at different disease stages (Mehdipour et al., 2017; Santoro et al., 2013). There are different classes of HDACis with 
diverse chemical structures; short chain fatty acids (or aliphatic acids), benzamides, cyclic peptides (the most structurally complex group), hydroxamic acids and miscellaneous compounds (Kim \& Bae, 2011; Nebbioso et al., 2012).

In the study conducted by Pathania R. and colleages, 5AC was used in combination with a HDACi named Butyrate. This combo therapy resulted in reduced cancer stem cells (CSCs) frequency and increased overall survival in murine mammary tumor model, through inhibition of growth-promoting molecules such as RAD51AP1 and SPC25 (Pathania et al., 2016). There are studies which show the mechanism of action for DNMTi (DAC) in combination with HDACis (SAHA or SB939) is derepression of long terminal repeats (LTRs) of ERV9/LTR12 family, which are silenced in normal cells (Brocks et al., 2017). In addition this study implicated that both of these agents can derepress LTR12C family expression but that full activation was gained through combination therapy. Synergistic effect of DNMTi and HDACi in induction of a proviral reporter construct has been also described in murine erythroleukemia cells (Lorincz et al., 2000). Several clinical studies have explored the combination of DNMTis and valpoic acid but this combination has not been used in phase 3 trials due to lack of efficacay and toxicity. (Griffiths \& Gore, 2008). Encouragingly, Juergens et al reported that combination of low dose 5AC and Etinostat in extensively pretreated patients with recurrent metastatic non-small cell lung cancer (NSCLC) was well tolerated and had compelling activity (Juergens et al., 2011). There are a handful of HDACis which have been used in combo with DNMTis in clinical trials, the detailed list of thse HDACis can be found in Table 2.

\section{DNMTis and chemotherapy/or radiation:}

Treatment with DNMTi in colorectal cancer cells improved the effects of classical chemotherapeutic agents such as 5-fluorouracil (5-FU) or oxaliplatin (Flis, Gnyszka, \& Flis, 
2014). Furthermore, it has been demonstrated that combination of DNMTi potentiated the chemotherapeutic effects of cisplatin and doxorubicin in ovarian, breast and lung cancer cell lines. In addition, the combination of DNMTi and chemotherapy can be also beneficial in treatment of relapsed patients who developed drug resistance to chemotherapy (Li et al., 2017).

\section{DNMTis and PARPis:}

Poly (ADP-ribose) Polyemerase 1 (PARP1) is an abundant nuclear protein that is involved in repair of DNA single-strand breaks (SSBs) and base-excision repair (BER). The PARP family in humans includes 17 proteins which have been identified based on their homology to the PARP1 (Ame, Spenlehauer, \& de Murcia, 2004). The catalytic activity of PARPs involves cleavage of $\mathrm{NAD}^{+}$into nicotinamide and ADP-ribose leading to formation of poly(ADP-ribose) polymers (Y. Shen, Aoyagi-Scharber, \& Wang, 2015). To this end, nicotinamide analogs were the first identified PARP inhibitors (PARPis) (Purnell \& Whish, 1980), which were effective in milimolar concentrations in vitro and had off-target effects (Milam \& Cleaver, 1984). Later on, more potent PARPis were discovered including the 4-amino-1,8-naphthalimide as one of the most potent ones (Banasik, Komura, Shimoyama, \& Ueda, 1992). PARP1 and PARP2 are the main targets of anticancer drugs due to their overlapping roles in DNA-damage repair (Schreiber et al., 2006). Veliparib (ABT-888) is a potent inhibitor of PARP1 and PARP2, which has oral bioavailability and its chemopotentiation and radiopotentiation has been evaluated in vitro and in vivo (Donawho et al., 2007). Talazoparib (BMN673) is an oral PARPi which provided significant benefits as monotherapy in patients with advanced breast cancer and a germ line BRAC1/2 mutation (Litton et al., 2018).

Non-covalent interactions of PARPi and DNMTi demonstrates a link between epigenetic and DNA-repair pathways. A study conducted by Muvarak, et al. showed the synergistic effect of 
low dose DNMTis $(5 \mathrm{AC}=150 \mathrm{nM})$ with nanomolar doses of Talazoparib. Pharmodynamic studies showed that DNMTis enhanced the cytotoxic effects of Talazoparib in BRCA breast cancer cells and AML subtypes, that are not responsive to PARPi as a single agent (Muvarak et al., 2016). Recently, it has been reported that combination of DNMTi (Guadecitabine) and PARPi (Talazoparib) sensitizes PARPi-resistant breast and ovarian cancers to PARPi independent of BRCA mutations, suggesting the potential for use of this combination in a clinical setting particularly in treatment of PARPi-resistant cancers (Pulliam et al., 2018).

\section{DNMTis and immune checkpoint blockade}

$\mathrm{T}$ cell exhaustion occurs due to chronic antigen exposure in cancer cells and is a natural innate mechanism that inhibits the prolonged immune responses that are accompanied with upregulation of programmed cell death protein-1 (PD-1) and cytotoxic T-lymphocyte-associated protein-4 (CTLA-4) cell surface receptors (Wherry, 2011). Anti-CTL4 and anti-PD1 which inhibit the interaction of CTLA-4 or PD-1 with their ligands have shown favorable responses in melanoma cancer patients, through reactivation of exhausted T cells (Hodi et al., 2010; Weber et al., 2015). However, other than melanoma cancer patients and small proportion of NSCLC patients the majority of cancer types do not respond to immune checkpoint therapy as monotherapy (Sharma \& Allison, 2015; Sui et al., 2018).

Recently, Goltz et al, have reported that there is a strong association between DNA hypomethylation of the PD-L1 promoter in AML and poor survival of patients, which suggests DNMTi induces upregulation of PD-L1 (Goltz et al., 2017). Taken together, aforementioned examples of DNMT hypomethylating agents efficacy in cancer immunity include: upregulation 
of cancer testis CTAs (Chou et al., 2012; James et al., 2013; Karpf et al., 2009; Siebenkas et al., 2017), genes of the major histocompatibility complexes presentation pathway in cancer cells (Lau et al., 2017) and induction of ERVs through viral mimicry (Chiappinelli et al., 2015; Roulois et al., 2015), suggesting that DNMTi in combination with immunotherapy may boost the clinical response and efficacy in larger spectrum of cancers.

\section{DNMTi and Vitamin C:}

The combination of DNMTi and Vitamin C (also known as ascorbic acid) as the cofactor of TET enzymes has synergistic effects, and through upregulation of dsRNA formation and an innate immune response leads to viral mimicry state (Liu et al., 2016). Since Vitamin C deficiency has been reported in patients with advanced cancer (Mayland, Bennett, \& Allan, 2005) and IV administration of vitamin $\mathrm{C}$ demonstrated its safety and tolerability in a Phase I clinical trials (Hoffer et al., 2008), this combination therapy can be tested in cancer patients.

\section{Summary and perspective:}

Despite promising results as anti-cancer compounds, on the efficacy of DNMTi due to their low specificity, chemical and metabolic instability, cytotoxity and poor oral bioavailability in patients (Kuendgen et al., 2018). Thus, among the features of DNMTis that need to be improved for clinical use are; I) Identifying preditive biomarkers for monitoring response to DNMTis, risk of reoccurance or better survival. II) Assessing the mechanisms that are involved in resistance to DNMTi or the ones involved in disease relapse in responder patients. III) Developing new chemical tools with DNA methyltransferase inhibitory effect. IV) Using non-nucleoside DNMTi to minimize the cytotoxicity that is due to incoporation of nucleoside inhibitors into DNA. 
In summary, this review highlights that epigenetic abnormalities observed in cancer can be targeted pharmacologically. However, Epi-drugs and specifically DNMTis have single agent efficacy only in select hematological malignancies and have not been effective for the treatment of solid tumors, underlying the need for novel combination regimens, biomarkers of response and novel DNMT inhibitors.

Additionally, the interplay of genetic and environment is involved in shaping divergent DNA methylation patterns between individuals (van Dongen et al., 2016), thus to improve the translational implication of these agents using a precision medicine approach may be useful.

\section{Conflict of interest}

DDC receives research funds from Nektar Therapeutics and Pfizer. All other authors declare no conflict of interest.

\section{Acknowledgements}

This work was supported by Canadian Institute of Health Research (CIHR) New Investigator Salary Award (201512MSH-360794-228629), Helen M Cooke professorship from Princess Margaret Cancer Foundation, Cancer Research Chair, CIHR Foundation Grant (FDN 148430), NSERC (489073) and Ontario Institute for Cancer Research (OICR) with funds from the province of Ontario to DDC. PM was supported by a Princess Margaret Postdoctoral fellowshipHold'em for life. 
Table 1. Features of 5AC, DAC and Oral Azacytidine for clinical use.

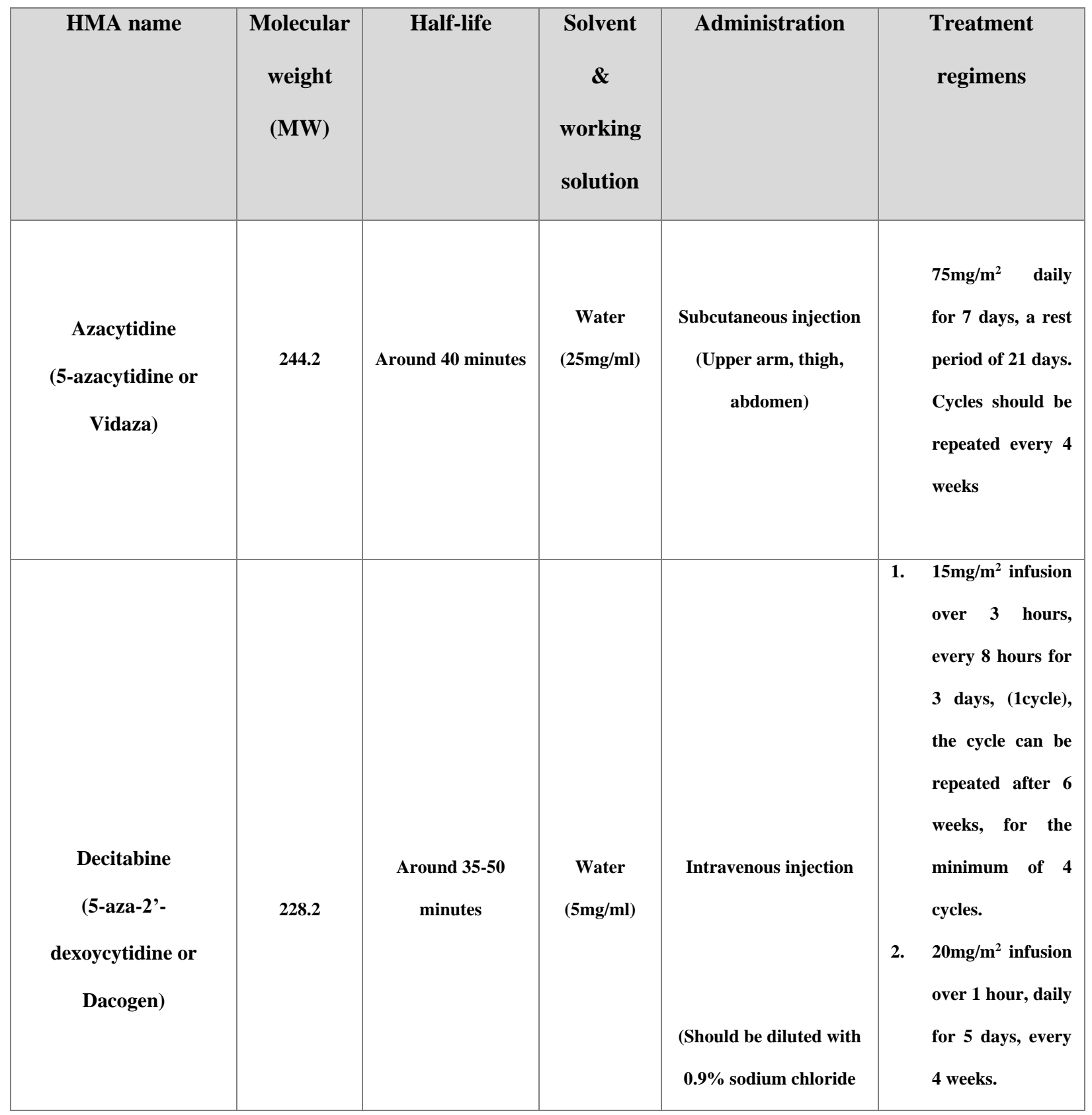




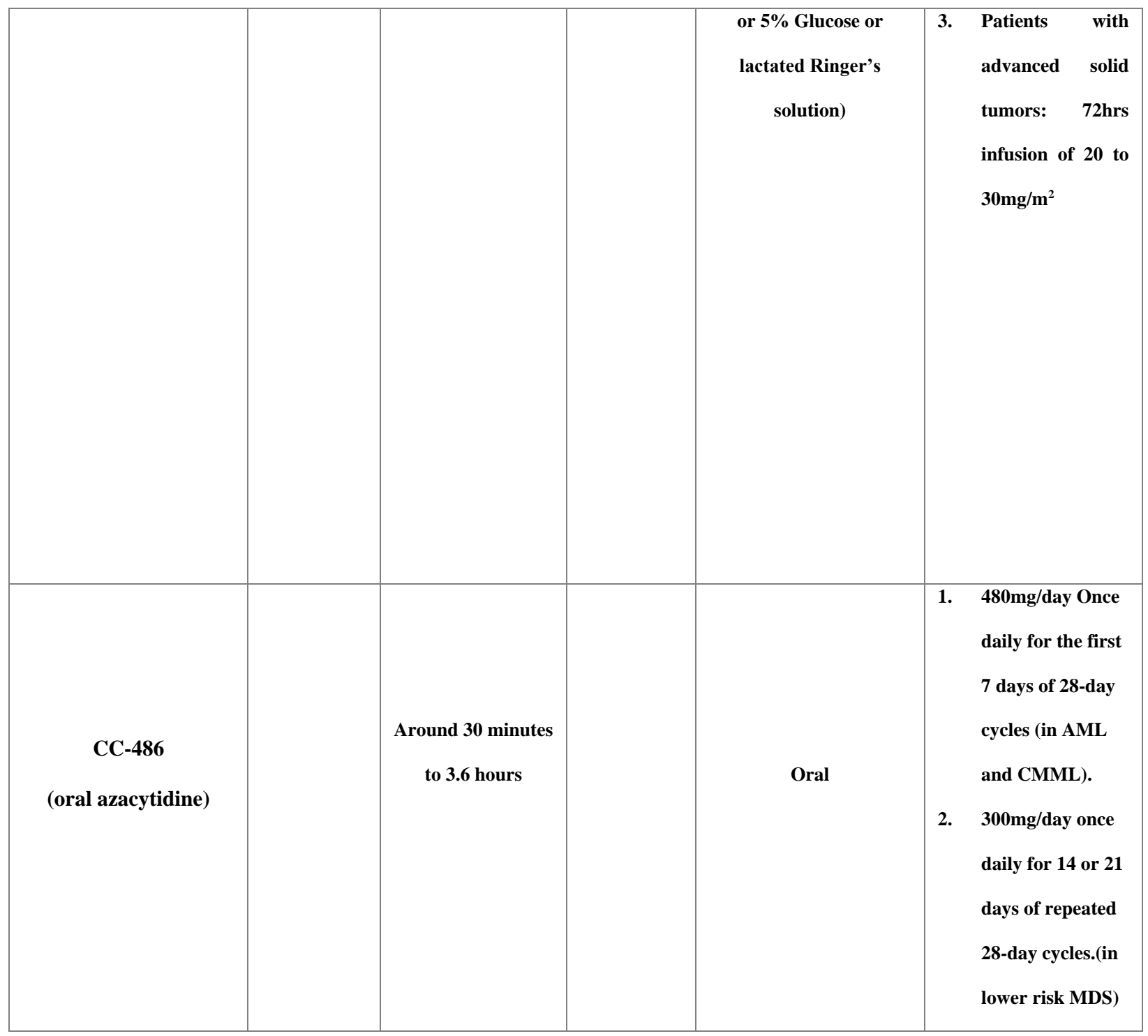


Table 2. Examples of completed clinical trials of DNMT inhibitors in combination with other compounds in hematological malignancies and solid tumors (https://clinicaltrials.gov/ct2/results?term=azacytidine\&Search=Apply\&recrs=e\&age_v=\&gndr= $\underline{\text { type }=\& \mathrm{rs} l \mathrm{t}=)}$

\begin{tabular}{|c|c|c|c|c|c|}
\hline Compounds & Cancer & Target & Phases & NCT number & $\begin{array}{l}\text { Number } \\
\text { Enrolled }\end{array}$ \\
\hline 5AC+Etinostat & $\begin{array}{l}\text { Elderly patients } \\
\text { with AML }\end{array}$ & $\begin{array}{l}\text { DNMT and } \\
\text { HDACs }\end{array}$ & Phase II & NCT01305499 & 108 \\
\hline 5AC+Etinsotat+Nivolumab & $\begin{array}{l}\text { Non-small lung } \\
\text { cancer }\end{array}$ & $\begin{array}{l}\text { DNMT, } \\
\text { HDACs and } \\
\text { PD1 }\end{array}$ & Phase II & NCT01928576 & 120 \\
\hline Vidaza+ Valproic acid & AML, MDS & $\begin{array}{l}\text { DNMT, } \\
\text { HDACs }\end{array}$ & Phase II & NCT02124174 & 50 \\
\hline $\begin{array}{l}\text { 5-azacytidine+Nivolumab+ } \\
\text { Ipilimumab }\end{array}$ & Leukemias & $\begin{array}{l}\text { DNMT, } \\
\text { HDAC and } \\
\text { PD1 }\end{array}$ & Phase II & NCT02397720 & 182 \\
\hline $\begin{array}{l}\text { Azacitidine } \\
\text { (C-486)+ Pembrolizumab }\end{array}$ & $\begin{array}{l}\text { Metastatic } \\
\text { melanoma }\end{array}$ & $\begin{array}{l}\text { DNMT and } \\
\text { PD1 }\end{array}$ & Phase II & NCT02816021 & 71 \\
\hline Oral 5-azacitidine + Romidepsin & $\begin{array}{l}\text { Advanced solid } \\
\text { tumors and } \\
\text { Virally } \\
\text { Mediated } \\
\text { Cancers and } \\
\text { Liposarcoma }\end{array}$ & $\begin{array}{l}\text { DNMT, } \\
\text { HDACs }\end{array}$ & Phase I & NCT01537744 & 18 \\
\hline
\end{tabular}




\begin{tabular}{|c|c|c|c|c|c|}
\hline CC-486 & $\begin{array}{l}\text { Nasopharyngeal } \\
\text { Neoplasms }\end{array}$ & DNMT & Phase II & NCT02269943 & 36 \\
\hline 5AC+Panobinostat & $\begin{array}{l}\text { MDS, CMML } \\
\text { and AML }\end{array}$ & $\begin{array}{l}\text { DNMT and } \\
\text { HDACs }\end{array}$ & Phase I & NCT01613976 & 10 \\
\hline 5AC+Belinostat & $\begin{array}{l}\text { Advanced } \\
\text { hematological } \\
\text { malignancies }\end{array}$ & $\begin{array}{l}\text { DNMT and } \\
\text { HDACs }\end{array}$ & Phase I & NCT00351975 & 56 \\
\hline DAC+ Valproic acid & $\begin{array}{l}\text { Non-small cell } \\
\text { lung cancer }\end{array}$ & $\begin{array}{l}\text { DNMT and } \\
\text { HDACs }\end{array}$ & Phase I & NCT00084981 & 25 \\
\hline DAC+Vorinostat & AML or MDS & $\begin{array}{l}\text { DNMT and } \\
\text { HDACs }\end{array}$ & Phase I & NCT00479232 & 71 \\
\hline SGI-110+ Carboplatin & Ovarian Cancer & $\begin{array}{l}\text { DNMT and } \\
\text { chemotherapy }\end{array}$ & Phase II & NCT01696032 & 120 \\
\hline $\begin{array}{l}\text { SGI- } \\
\text { 110+Durvalumab+Tremelimumab }\end{array}$ & $\begin{array}{l}\text { Small cell lung } \\
\text { Cancer }\end{array}$ & $\begin{array}{l}\text { DNMT, PD1 } \\
\text { and CTLA4 }\end{array}$ & Phase I & NCT03085849 & 2 \\
\hline $\begin{array}{l}\text { DAC+Induction chemotherapy ( } \\
\text { Daunorubicin, Cytarabine and } \\
\text { Etoposide) }\end{array}$ & Pediatric AML & DNMT & Phase II & NCT01177540 & 25 \\
\hline DAC+ induction chemotherapy & AML & DNMT & PhaseI & NCT00538876 & 30 \\
\hline 5AC+ Vorinostat & Lymphoma & $\begin{array}{l}\text { DNMT and } \\
\text { HDACs }\end{array}$ & $\begin{array}{l}5 \mathrm{AC} \\
\text { (phase I) } \\
\text { Vorinostat } \\
\text { (Phase II) }\end{array}$ & NCT01120834 & 17 \\
\hline
\end{tabular}




\section{References:}

Agoston, A. T., Argani, P., Yegnasubramanian, S., De Marzo, A. M., Ansari-Lari, M. A., Hicks, J. L., et al. (2005). Increased protein stability causes DNA methyltransferase 1 dysregulation in breast cancer. J Biol Chem, 280(18), 18302-18310.

Aimiuwu, J., Wang, H., Chen, P., Xie, Z., Wang, J., Liu, S., et al. (2012). RNA-dependent inhibition of ribonucleotide reductase is a major pathway for 5-azacytidine activity in acute myeloid leukemia. Blood, 119(22), 5229-5238.

Aloia, L., Di Stefano, B., \& Di Croce, L. (2013). Polycomb complexes in stem cells and embryonic development. Development, 140(12), 2525-2534.

Ame, J. C., Spenlehauer, C., \& de Murcia, G. (2004). The PARP superfamily. Bioessays, 26(8), 882-893.

Arai, E., Kanai, Y., Ushijima, S., Fujimoto, H., Mukai, K., \& Hirohashi, S. (2006). Regional DNA hypermethylation and DNA methyltransferase (DNMT) 1 protein overexpression in both renal tumors and corresponding nontumorous renal tissues. Int J Cancer, 119(2), 288-296.

Avvakumov, G. V., Walker, J. R., Xue, S., Li, Y., Duan, S., Bronner, C., et al. (2008). Structural basis for recognition of hemi-methylated DNA by the SRA domain of human UHRF1. Nature, 455(7214), 822-825.

Banasik, M., Komura, H., Shimoyama, M., \& Ueda, K. (1992). Specific inhibitors of poly(ADPribose) synthetase and mono(ADP-ribosyl)transferase. J Biol Chem, 267(3), 1569-1575.

Baylin, S. B., \& Jones, P. A. (2011). A decade of exploring the cancer epigenome - biological and translational implications. Nat Rev Cancer, 11(10), 726-734.

Bedford, M. T., \& van Helden, P. D. (1987). Hypomethylation of DNA in pathological conditions of the human prostate. Cancer Res, 47(20), 5274-5276.

Bernstein, B. E., Mikkelsen, T. S., Xie, X., Kamal, M., Huebert, D. J., Cuff, J., et al. (2006). A bivalent chromatin structure marks key developmental genes in embryonic stem cells. Cell, 125(2), 315-326.

Birger, Y., Shemer, R., Perk, J., \& Razin, A. (1999). The imprinting box of the mouse Igf2r gene. Nature, 397(6714), 84-88.

Bogdanovic, O., \& Veenstra, G. J. (2009). DNA methylation and methyl-CpG binding proteins: developmental requirements and function. Chromosoma, 118(5), 549-565.

Bogenberger, J. M., Kornblau, S. M., Pierceall, W. E., Lena, R., Chow, D., Shi, C. X., et al. (2014). BCL-2 family proteins as 5-Azacytidine-sensitizing targets and determinants of response in myeloid malignancies. Leukemia, 28(8), 1657-1665.

Boiani, M., \& Scholer, H. R. (2005). Regulatory networks in embryo-derived pluripotent stem cells. Nat Rev Mol Cell Biol, 6(11), 872-884.

Bourc'his, D., Xu, G. L., Lin, C. S., Bollman, B., \& Bestor, T. H. (2001). Dnmt3L and the establishment of maternal genomic imprints. Science, 294(5551), 2536-2539.

Brocks, D., Schmidt, C. R., Daskalakis, M., Jang, H. S., Shah, N. M., Li, D., et al. (2017). DNMT and HDAC inhibitors induce cryptic transcription start sites encoded in long terminal repeats. Nat Genet, 49(7), 1052-1060.

Cameron, E. E., Bachman, K. E., Myohanen, S., Herman, J. G., \& Baylin, S. B. (1999). Synergy of demethylation and histone deacetylase inhibition in the re-expression of genes silenced in cancer. Nat Genet, 21(1), 103-107. 
Cattanach, B. M., \& Kirk, M. (1985). Differential activity of maternally and paternally derived chromosome regions in mice. Nature, 315(6019), 496-498.

Cedar, H., \& Bergman, Y. (2012). Programming of DNA methylation patterns. Annu Rev Biochem, 81, 97-117.

Chedin, F., Lieber, M. R., \& Hsieh, C. L. (2002). The DNA methyltransferase-like protein DNMT3L stimulates de novo methylation by Dnmt3a. Proc Natl Acad Sci U S A, 99(26), 16916-16921.

Chiappinelli, K. B., Strissel, P. L., Desrichard, A., Li, H., Henke, C., Akman, B., et al. (2015). Inhibiting DNA Methylation Causes an Interferon Response in Cancer via dsRNA Including Endogenous Retroviruses. Cell, 162(5), 974-986.

Chou, J., Voong, L. N., Mortales, C. L., Towlerton, A. M., Pollack, S. M., Chen, X., et al. (2012). Epigenetic modulation to enable antigen-specific T-cell therapy of colorectal cancer. J Immunother, 35(2), 131-141.

Chou, W. C., Chou, S. C., Liu, C. Y., Chen, C. Y., Hou, H. A., Kuo, Y. Y., et al. (2011). TET2 mutation is an unfavorable prognostic factor in acute myeloid leukemia patients with intermediate-risk cytogenetics. Blood, 118(14), 3803-3810.

Clouaire, T., \& Stancheva, I. (2008). Methyl-CpG binding proteins: specialized transcriptional repressors or structural components of chromatin? Cell Mol Life Sci, 65(10), 1509-1522.

Cogle, C. R., Scott, B. L., Boyd, T., \& Garcia-Manero, G. (2015). Oral Azacitidine (CC-486) for the Treatment of Myelodysplastic Syndromes and Acute Myeloid Leukemia. Oncologist, 20(12), 1404-1412.

De Carvalho, D. D., Sharma, S., You, J. S., Su, S. F., Taberlay, P. C., Kelly, T. K., et al. (2012). DNA methylation screening identifies driver epigenetic events of cancer cell survival. Cancer Cell, 21(5), 655-667.

de Mendoza, A., Bonnet, A., Vargas-Landin, D. B., Ji, N., Li, H., Yang, F., et al. (2018). Recurrent acquisition of cytosine methyltransferases into eukaryotic retrotransposons. Nat Commun, 9(1), 1341.

Derissen, E. J., Beijnen, J. H., \& Schellens, J. H. (2013). Concise drug review: azacitidine and decitabine. Oncologist, 18(5), 619-624.

DeZern, A. E. (2015). Nine years without a new FDA-approved therapy for MDS: how can we break through the impasse? Hematology Am Soc Hematol Educ Program, 2015, 308-316.

Dominguez, P. M., \& Shaknovich, R. (2014). Epigenetic function of activation-induced cytidine deaminase and its link to lymphomagenesis. Front Immunol, 5, 642.

Donawho, C. K., Luo, Y., Luo, Y., Penning, T. D., Bauch, J. L., Bouska, J. J., et al. (2007). ABT-888, an orally active poly(ADP-ribose) polymerase inhibitor that potentiates DNAdamaging agents in preclinical tumor models. Clin Cancer Res, 13(9), 2728-2737.

Dong, K. B., Maksakova, I. A., Mohn, F., Leung, D., Appanah, R., Lee, S., et al. (2008). DNA methylation in ES cells requires the lysine methyltransferase G9a but not its catalytic activity. EMBO J, 27(20), 2691-2701.

Du, Z., Song, J., Wang, Y., Zhao, Y., Guda, K., Yang, S., et al. (2010). DNMT1 stability is regulated by proteins coordinating deubiquitination and acetylation-driven ubiquitination. Sci Signal, 3(146), ra80.

Esteller, M. (2007). Cancer epigenomics: DNA methylomes and histone-modification maps. Nat Rev Genet, 8(4), 286-298.

Etoh, T., Kanai, Y., Ushijima, S., Nakagawa, T., Nakanishi, Y., Sasako, M., et al. (2004). Increased DNA methyltransferase 1 (DNMT1) protein expression correlates significantly 
with poorer tumor differentiation and frequent DNA hypermethylation of multiple CpG islands in gastric cancers. Am J Pathol, 164(2), 689-699.

Feinberg, A. P., Gehrke, C. W., Kuo, K. C., \& Ehrlich, M. (1988). Reduced genomic 5methylcytosine content in human colonic neoplasia. Cancer Res, 48(5), 1159-1161.

Fenaux, P., Mufti, G. J., Hellstrom-Lindberg, E., Santini, V., Finelli, C., Giagounidis, A., et al. (2009). Efficacy of azacitidine compared with that of conventional care regimens in the treatment of higher-risk myelodysplastic syndromes: a randomised, open-label, phase III study. Lancet Oncol, 10(3), 223-232.

Figueroa, M. E., Abdel-Wahab, O., Lu, C., Ward, P. S., Patel, J., Shih, A., et al. (2010). Leukemic IDH1 and IDH2 mutations result in a hypermethylation phenotype, disrupt TET2 function, and impair hematopoietic differentiation. Cancer Cell, 18(6), 553-567.

Flis, S., Gnyszka, A., \& Flis, K. (2014). DNA methyltransferase inhibitors improve the effect of chemotherapeutic agents in SW48 and HT-29 colorectal cancer cells. PLoS One, 9(3), e92305.

Gal-Yam, E. N., Egger, G., Iniguez, L., Holster, H., Einarsson, S., Zhang, X., et al. (2008). Frequent switching of Polycomb repressive marks and DNA hypermethylation in the PC3 prostate cancer cell line. Proc Natl Acad Sci U S A, 105(35), 12979-12984.

Gama-Sosa, M. A., Slagel, V. A., Trewyn, R. W., Oxenhandler, R., Kuo, K. C., Gehrke, C. W., et al. (1983). The 5-methylcytosine content of DNA from human tumors. Nucleic Acids Res, 11(19), 6883-6894.

Gaudet, F., Hodgson, J. G., Eden, A., Jackson-Grusby, L., Dausman, J., Gray, J. W., et al. (2003). Induction of tumors in mice by genomic hypomethylation. Science, 300(5618), 489-492.

Goltz, D., Gevensleben, H., Grunen, S., Dietrich, J., Kristiansen, G., Landsberg, J., et al. (2017). PD-L1 (CD274) promoter methylation predicts survival in patients with acute myeloid leukemia. Leukemia, 31(3), 738-743.

Goto, T., \& Monk, M. (1998). Regulation of X-chromosome inactivation in development in mice and humans. Microbiol Mol Biol Rev, 62(2), 362-378.

Gowher, H., Liebert, K., Hermann, A., Xu, G., \& Jeltsch, A. (2005). Mechanism of stimulation of catalytic activity of Dnmt3A and Dnmt3B DNA-(cytosine-C5)-methyltransferases by Dnmt3L. J Biol Chem, 280(14), 13341-13348.

Gravina, G. L., Festuccia, C., Marampon, F., Popov, V. M., Pestell, R. G., Zani, B. M., et al. (2010). Biological rationale for the use of DNA methyltransferase inhibitors as new strategy for modulation of tumor response to chemotherapy and radiation. Mol Cancer, 9, 305.

Griffiths, E. A., \& Gore, S. D. (2008). DNA methyltransferase inhibitors: class effect or unique agents? Leuk Lymphoma, 49(4), 650-651.

Gros, C., Fahy, J., Halby, L., Dufau, I., Erdmann, A., Gregoire, J. M., et al. (2012). DNA methylation inhibitors in cancer: recent and future approaches. Biochimie, 94(11), 22802296.

Gros, C., Fleury, L., Nahoum, V., Faux, C., Valente, S., Labella, D., et al. (2015). New insights on the mechanism of quinoline-based DNA Methyltransferase inhibitors. J Biol Chem, 290(10), 6293-6302.

Herman, J. G., \& Baylin, S. B. (2003). Gene silencing in cancer in association with promoter hypermethylation. N Engl J Med, 349(21), 2042-2054. 
Hodi, F. S., O'Day, S. J., McDermott, D. F., Weber, R. W., Sosman, J. A., Haanen, J. B., et al. (2010). Improved survival with ipilimumab in patients with metastatic melanoma. $N$ Engl J Med, 363(8), 711-723.

Hoffer, L. J., Levine, M., Assouline, S., Melnychuk, D., Padayatty, S. J., Rosadiuk, K., et al. (2008). Phase I clinical trial of i.v. ascorbic acid in advanced malignancy. Ann Oncol, 19(11), 1969-1974.

Hosseini, A., \& Minucci, S. (2017). A comprehensive review of lysine-specific demethylase 1 and its roles in cancer. Epigenomics, 9(8), 1123-1142.

Hosseini, A., \& Minucci, S. (2018). Chapter 6 - Alterations of Histone Modifications in Cancer. In T. O. Tollefsbol (Ed.), Epigenetics in Human Disease (Second Edition) (Vol. 6, pp. 141-217): Academic Press.

Huff, J. T., \& Zilberman, D. (2014). Dnmt1-independent CG methylation contributes to nucleosome positioning in diverse eukaryotes. Cell, 156(6), 1286-1297.

Hughes, L. A., Melotte, V., de Schrijver, J., de Maat, M., Smit, V. T., Bovee, J. V., et al. (2013). The CpG island methylator phenotype: what's in a name? Cancer Res, 73(19), 58585868.

Irizarry, R. A., Ladd-Acosta, C., Wen, B., Wu, Z., Montano, C., Onyango, P., et al. (2009). The human colon cancer methylome shows similar hypo- and hypermethylation at conserved tissue-specific CpG island shores. Nat Genet, 41(2), 178-186.

Issa, J. P. (2012). DNA methylation as a clinical marker in oncology. J Clin Oncol, 30(20), 2566-2568.

Ito, S., Shen, L., Dai, Q., Wu, S. C., Collins, L. B., Swenberg, J. A., et al. (2011). Tet proteins can convert 5-methylcytosine to 5-formylcytosine and 5-carboxylcytosine. Science, 333(6047), 1300-1303.

Jabbour, E., Issa, J. P., Garcia-Manero, G., \& Kantarjian, H. (2008). Evolution of decitabine development: accomplishments, ongoing investigations, and future strategies. Cancer, 112(11), 2341-2351.

Jackson-Grusby, L., Laird, P. W., Magge, S. N., Moeller, B. J., \& Jaenisch, R. (1997). Mutagenicity of 5-aza-2'-deoxycytidine is mediated by the mammalian DNA methyltransferase. Proc Natl Acad Sci U S A, 94(9), 4681-4685.

James, S. R., Cedeno, C. D., Sharma, A., Zhang, W., Mohler, J. L., Odunsi, K., et al. (2013). DNA methylation and nucleosome occupancy regulate the cancer germline antigen gene MAGEA11. Epigenetics, 8(8), 849-863.

Jones, C. L., Stevens, B. M., D'Alessandro, A., Reisz, J. A., Culp-Hill, R., Nemkov, T., et al. (2018). Inhibition of Amino Acid Metabolism Selectively Targets Human Leukemia Stem Cells. Cancer Cell, 34(5), 724-740 e724.

Jones, P. A., \& Baylin, S. B. (2007). The epigenomics of cancer. Cell, 128(4), 683-692.

Jones, P. A., \& Laird, P. W. (1999). Cancer epigenetics comes of age. Nat Genet, 21(2), 163167.

Jones, P. A., Ohtani, H., Chakravarthy, A., \& De Carvalho, D. D. (2019). Epigenetic therapy in immune-oncology. Nat Rev Cancer.

Jones, P. A., \& Taylor, S. M. (1980). Cellular differentiation, cytidine analogs and DNA methylation. Cell, 20(1), 85-93.

Juergens, R. A., Wrangle, J., Vendetti, F. P., Murphy, S. C., Zhao, M., Coleman, B., et al. (2011). Combination epigenetic therapy has efficacy in patients with refractory advanced non-small cell lung cancer. Cancer Discov, 1(7), 598-607. 
Juttermann, R., Li, E., \& Jaenisch, R. (1994). Toxicity of 5-aza-2'-deoxycytidine to mammalian cells is mediated primarily by covalent trapping of DNA methyltransferase rather than DNA demethylation. Proc Natl Acad Sci U S A, 91(25), 11797-11801.

Kaminskas, E., Farrell, A. T., Wang, Y. C., Sridhara, R., \& Pazdur, R. (2005). FDA drug approval summary: azacitidine (5-azacytidine, Vidaza) for injectable suspension. Oncologist, 10(3), 176-182.

Kaneda, M., Okano, M., Hata, K., Sado, T., Tsujimoto, N., Li, E., et al. (2004). Essential role for de novo DNA methyltransferase Dnmt3a in paternal and maternal imprinting. Nature, 429(6994), 900-903.

Kantarjian, H. M., Roboz, G. J., Kropf, P. L., Yee, K. W. L., O'Connell, C. L., Tibes, R., et al. (2017). Guadecitabine (SGI-110) in treatment-naive patients with acute myeloid leukaemia: phase 2 results from a multicentre, randomised, phase 1/2 trial. The Lancet. Oncology, 18(10), 1317-1326.

Karpf, A. R., Bai, S., James, S. R., Mohler, J. L., \& Wilson, E. M. (2009). Increased expression of androgen receptor coregulator MAGE-11 in prostate cancer by DNA hypomethylation and cyclic AMP. Mol Cancer Res, 7(4), 523-535.

Kelly, T. K., De Carvalho, D. D., \& Jones, P. A. (2010). Epigenetic modifications as therapeutic targets. Nat Biotechnol, 28(10), 1069-1078.

Kim, H., Kwon, Y. M., Kim, J. S., Han, J., Shim, Y. M., Park, J., et al. (2006). Elevated mRNA levels of DNA methyltransferase-1 as an independent prognostic factor in primary nonsmall cell lung cancer. Cancer, 107(5), 1042-1049.

Kim, H. J., \& Bae, S. C. (2011). Histone deacetylase inhibitors: molecular mechanisms of action and clinical trials as anti-cancer drugs. Am J Transl Res, 3(2), 166-179.

Kohli, R. M., \& Zhang, Y. (2013). TET enzymes, TDG and the dynamics of DNA demethylation. Nature, 502(7472), 472-479.

Kuendgen, A., Muller-Thomas, C., Lauseker, M., Haferlach, T., Urbaniak, P., Schroeder, T., et al. (2018). Efficacy of azacitidine is independent of molecular and clinical characteristics - an analysis of 128 patients with myelodysplastic syndromes or acute myeloid leukemia and a review of the literature. Oncotarget, 9(45), 27882-27894.

Lagadinou, E. D., Sach, A., Callahan, K., Rossi, R. M., Neering, S. J., Minhajuddin, M., et al. (2013). BCL-2 inhibition targets oxidative phosphorylation and selectively eradicates quiescent human leukemia stem cells. Cell Stem Cell, 12(3), 329-341.

Landau, D. A., Tausch, E., Taylor-Weiner, A. N., Stewart, C., Reiter, J. G., Bahlo, J., et al. (2015). Mutations driving CLL and their evolution in progression and relapse. Nature, 526(7574), 525-530.

Langemeijer, S. M., Kuiper, R. P., Berends, M., Knops, R., Aslanyan, M. G., Massop, M., et al. (2009). Acquired mutations in TET2 are common in myelodysplastic syndromes. Nat Genet, 41(7), 838-842.

Lau, J., Cheung, J., Navarro, A., Lianoglou, S., Haley, B., Totpal, K., et al. (2017). Tumour and host cell PD-L1 is required to mediate suppression of anti-tumour immunity in mice. Nat Commun, 8, 14572.

Lavelle, D., Vaitkus, K., Ling, Y., Ruiz, M. A., Mahfouz, R., Ng, K. P., et al. (2012). Effects of tetrahydrouridine on pharmacokinetics and pharmacodynamics of oral decitabine. Blood, $119(5), 1240-1247$. 
Lee, T., Karon, M., \& Momparler, R. L. (1974). Kinetic studies on phosphorylation of 5azacytidine with the purified uridine-cytidine kinase from calf thymus. Cancer Res, 34(10), 2482-2488.

Lewis, J. D., Meehan, R. R., Henzel, W. J., Maurer-Fogy, I., Jeppesen, P., Klein, F., et al. (1992). Purification, sequence, and cellular localization of a novel chromosomal protein that binds to methylated DNA. Cell, 69(6), 905-914.

Li, E., Beard, C., \& Jaenisch, R. (1993). Role for DNA methylation in genomic imprinting. Nature, 366(6453), 362-365.

Li, E., Bestor, T. H., \& Jaenisch, R. (1992). Targeted mutation of the DNA methyltransferase gene results in embryonic lethality. Cell, 69(6), 915-926.

Li, J., Hao, D., Wang, L., Wang, H., Wang, Y., Zhao, Z., et al. (2017). Epigenetic targeting drugs potentiate chemotherapeutic effects in solid tumor therapy. Sci Rep, 7(1), 4035.

Li, T., Wang, L., Du, Y., Xie, S., Yang, X., Lian, F., et al. (2018). Structural and mechanistic insights into UHRF1-mediated DNMT1 activation in the maintenance DNA methylation. Nucleic Acids Res, 46(6), 3218-3231.

Liang, G., \& Weisenberger, D. J. (2017). DNA methylation aberrancies as a guide for surveillance and treatment of human cancers. Epigenetics, 12(6), 416-432.

Lin, C. H., Hsieh, S. Y., Sheen, I. S., Lee, W. C., Chen, T. C., Shyu, W. C., et al. (2001). Genome-wide hypomethylation in hepatocellular carcinogenesis. Cancer Res, 61(10), 4238-4243.

Litton, J. K., Rugo, H. S., Ettl, J., Hurvitz, S. A., Goncalves, A., Lee, K. H., et al. (2018). Talazoparib in Patients with Advanced Breast Cancer and a Germline BRCA Mutation. $N$ Engl J Med, 379(8), 753-763.

Liu, M., Ohtani, H., Zhou, W., Orskov, A. D., Charlet, J., Zhang, Y. W., et al. (2016). Vitamin C increases viral mimicry induced by 5-aza-2'-deoxycytidine. Proc Natl Acad Sci U S A, 113(37), 10238-10244.

Long, M. D., Smiraglia, D. J., \& Campbell, M. J. (2017). The Genomic Impact of DNA CpG Methylation on Gene Expression; Relationships in Prostate Cancer. Biomolecules, 7(1).

Lorincz, M. C., Schubeler, D., Goeke, S. C., Walters, M., Groudine, M., \& Martin, D. I. (2000). Dynamic analysis of proviral induction and De Novo methylation: implications for a histone deacetylase-independent, methylation density-dependent mechanism of transcriptional repression. Mol Cell Biol, 20(3), 842-850.

Lyko, F. (2018). The DNA methyltransferase family: a versatile toolkit for epigenetic regulation. Nat Rev Genet, 19(2), 81-92.

Malik, P., \& Cashen, A. F. (2014). Decitabine in the treatment of acute myeloid leukemia in elderly patients. Cancer Manag Res, 6, 53-61.

Margueron, R., \& Reinberg, D. (2011). The Polycomb complex PRC2 and its mark in life. Nature, 469(7330), 343-349.

Mayland, C. R., Bennett, M. I., \& Allan, K. (2005). Vitamin C deficiency in cancer patients. Palliat Med, 19(1), 17-20.

McGrath, J., \& Solter, D. (1984). Completion of mouse embryogenesis requires both the maternal and paternal genomes. Cell, 37(1), 179-183.

Mehdipour, P., Santoro, F., Botrugno, O. A., Romanenghi, M., Pagliuca, C., Matthews, G. M., et al. (2017). HDAC3 activity is required for initiation of leukemogenesis in acute promyelocytic leukemia. Leukemia, 31(4), 995-997. 
Meissner, A., Mikkelsen, T. S., Gu, H., Wernig, M., Hanna, J., Sivachenko, A., et al. (2008). Genome-scale DNA methylation maps of pluripotent and differentiated cells. Nature, 454(7205), 766-770.

Milam, K. M., \& Cleaver, J. E. (1984). Inhibitors of poly(adenosine diphosphate-ribose) synthesis: effect on other metabolic processes. Science, 223(4636), 589-591.

Mohn, F., Weber, M., Rebhan, M., Roloff, T. C., Richter, J., Stadler, M. B., et al. (2008). Lineage-specific polycomb targets and de novo DNA methylation define restriction and potential of neuronal progenitors. Mol Cell, 30(6), 755-766.

Momparler, R. L. (2005). Pharmacology of 5-Aza-2'-deoxycytidine (decitabine). Semin Hematol, 42(3 Suppl 2), S9-16.

Momparler, R. L., Bouchard, J., Onetto, N., \& Rivard, G. E. (1984). 5-aza-2'-deoxycytidine therapy in patients with acute leukemia inhibits DNA methylation. Leuk Res, 8(2), 181185.

Mottamal, M., Zheng, S., Huang, T. L., \& Wang, G. (2015). Histone deacetylase inhibitors in clinical studies as templates for new anticancer agents. Molecules, 20(3), 3898-3941.

Muvarak, N. E., Chowdhury, K., Xia, L., Robert, C., Choi, E. Y., Cai, Y., et al. (2016). Enhancing the Cytotoxic Effects of PARP Inhibitors with DNA Demethylating Agents A Potential Therapy for Cancer. Cancer Cell, 30(4), 637-650.

Nebbioso, A., Carafa, V., Benedetti, R., \& Altucci, L. (2012). Trials with 'epigenetic' drugs: an update. Mol Oncol, 6(6), 657-682.

Neri, F., Krepelova, A., Incarnato, D., Maldotti, M., Parlato, C., Galvagni, F., et al. (2013). Dnmt3L antagonizes DNA methylation at bivalent promoters and favors DNA methylation at gene bodies in ESCs. Cell, 155(1), 121-134.

Nicholls, R. D., Knoll, J. H., Butler, M. G., Karam, S., \& Lalande, M. (1989). Genetic imprinting suggested by maternal heterodisomy in nondeletion Prader-Willi syndrome. Nature, 342(6247), 281-285.

Nieto, M., Samper, E., Fraga, M. F., Gonzalez de Buitrago, G., Esteller, M., \& Serrano, M. (2004). The absence of p53 is critical for the induction of apoptosis by 5-aza-2'deoxycytidine. Oncogene, 23(3), 735-743.

Ohm, J. E., McGarvey, K. M., Yu, X., Cheng, L., Schuebel, K. E., Cope, L., et al. (2007). A stem cell-like chromatin pattern may predispose tumor suppressor genes to DNA hypermethylation and heritable silencing. Nat Genet, 39(2), 237-242.

Okano, M., Bell, D. W., Haber, D. A., \& Li, E. (1999). DNA methyltransferases Dnmt3a and Dnmt3b are essential for de novo methylation and mammalian development. Cell, 99(3), 247-257.

Okano, M., Xie, S., \& Li, E. (1998). Dnmt2 is not required for de novo and maintenance methylation of viral DNA in embryonic stem cells. Nucleic Acids Res, 26(11), 25362540.

Pappalardi, M. B., Cockerill, M., Handler, J. L., Stowell, A., Keenan, K., Sherk, C. S., et al. (2018). Abstract 2994: Discovery of selective, noncovalent small molecule inhibitors of DNMT1 as an alternative to traditional DNA hypomethylating agents. Cancer Research, 78(13 Supplement), 2994-2994.

Pathania, R., Ramachandran, S., Mariappan, G., Thakur, P., Shi, H., Choi, J. H., et al. (2016). Combined Inhibition of DNMT and HDAC Blocks the Tumorigenicity of Cancer Stemlike Cells and Attenuates Mammary Tumor Growth. Cancer Res, 76(11), 3224-3235. 
Peng, D. F., Kanai, Y., Sawada, M., Ushijima, S., Hiraoka, N., Kitazawa, S., et al. (2006). DNA methylation of multiple tumor-related genes in association with overexpression of DNA methyltransferase 1 (DNMT1) during multistage carcinogenesis of the pancreas. Carcinogenesis, 27(6), 1160-1168.

Peters, J. (2014). The role of genomic imprinting in biology and disease: an expanding view. Nat Rev Genet, 15(8), 517-530.

Portela, A., \& Esteller, M. (2010). Epigenetic modifications and human disease. Nat Biotechnol, 28(10), 1057-1068.

Pulliam, N., Fang, F., Ozes, A. R., Tang, J., Adewuyi, A., Keer, H., et al. (2018). An Effective Epigenetic-PARP Inhibitor Combination Therapy for Breast and Ovarian Cancers Independent of BRCA Mutations. Clin Cancer Res, 24(13), 3163-3175.

Purnell, M. R., \& Whish, W. J. (1980). Novel inhibitors of poly(ADP-ribose) synthetase. Biochem J, 185(3), 775-777.

Quivoron, C., Couronne, L., Della Valle, V., Lopez, C. K., Plo, I., Wagner-Ballon, O., et al. (2011). TET2 inactivation results in pleiotropic hematopoietic abnormalities in mouse and is a recurrent event during human lymphomagenesis. Cancer Cell, 20(1), 25-38.

Rauch, T., Wang, Z., Zhang, X., Zhong, X., Wu, X., Lau, S. K., et al. (2007). Homeobox gene methylation in lung cancer studied by genome-wide analysis with a microarray-based methylated CpG island recovery assay. Proc Natl Acad Sci U S A, 104(13), 5527-5532.

Rice, K. L., Hormaeche, I., \& Licht, J. D. (2007). Epigenetic regulation of normal and malignant hematopoiesis. Oncogene, 26(47), 6697-6714.

Ritchie, E. K., Feldman, E. J., Christos, P. J., Rohan, S. D., Lagassa, C. B., Ippoliti, C., et al. (2013). Decitabine in patients with newly diagnosed and relapsed acute myeloid leukemia. Leuk Lymphoma, 54(9), 2003-2007.

Rivard, G. E., Momparler, R. L., Demers, J., Benoit, P., Raymond, R., Lin, K., et al. (1981). Phase I study on 5-aza-2'-deoxycytidine in children with acute leukemia. Leuk Res, 5(6), 453-462.

Robertson, K. D. (2005). DNA methylation and human disease. Nat Rev Genet, 6(8), 597-610.

Rodriguez, J., Vives, L., Jorda, M., Morales, C., Munoz, M., Vendrell, E., et al. (2008). Genomewide tracking of unmethylated DNA Alu repeats in normal and cancer cells. Nucleic Acids Res, 36(3), 770-784.

Roulois, D., Loo Yau, H., Singhania, R., Wang, Y., Danesh, A., Shen, S. Y., et al. (2015). DNADemethylating Agents Target Colorectal Cancer Cells by Inducing Viral Mimicry by Endogenous Transcripts. Cell, 162(5), 961-973.

Saito, Y., Kanai, Y., Nakagawa, T., Sakamoto, M., Saito, H., Ishii, H., et al. (2003). Increased protein expression of DNA methyltransferase (DNMT) 1 is significantly correlated with the malignant potential and poor prognosis of human hepatocellular carcinomas. Int $J$ Cancer, 105(4), 527-532.

Santoro, F., Botrugno, O. A., Dal Zuffo, R., Pallavicini, I., Matthews, G. M., Cluse, L., et al. (2013). A dual role for Hdac1: oncosuppressor in tumorigenesis, oncogene in tumor maintenance. Blood, 121(17), 3459-3468.

Sarda, S., \& Hannenhalli, S. (2018). Orphan CpG islands as alternative promoters. Transcription, 9(3), 171-176.

Savona, M. R., Malcovati, L., Komrokji, R., Tiu, R. V., Mughal, T. I., Orazi, A., et al. (2015). An international consortium proposal of uniform response criteria for 
myelodysplastic/myeloproliferative neoplasms (MDS/MPN) in adults. Blood, 125(12), 1857-1865.

Schaefer, C. B., Ooi, S. K., Bestor, T. H., \& Bourc'his, D. (2007). Epigenetic decisions in mammalian germ cells. Science, 316(5823), 398-399.

Schuh, A. C., Dohner, H., Pleyer, L., Seymour, J. F., Fenaux, P., \& Dombret, H. (2017). Azacitidine in adult patients with acute myeloid leukemia. Crit Rev Oncol Hematol, 116, 159-177.

Shamas-Din, A., Kale, J., Leber, B., \& Andrews, D. W. (2013). Mechanisms of action of Bcl-2 family proteins. Cold Spring Harb Perspect Biol, 5(4), a008714.

Sharif, J., Muto, M., Takebayashi, S., Suetake, I., Iwamatsu, A., Endo, T. A., et al. (2007). The SRA protein Np95 mediates epigenetic inheritance by recruiting Dnmt1 to methylated DNA. Nature, 450(7171), 908-912.

Sharma, P., \& Allison, J. P. (2015). Immune checkpoint targeting in cancer therapy: toward combination strategies with curative potential. Cell, 161(2), 205-214.

Sharp, A. J., Stathaki, E., Migliavacca, E., Brahmachary, M., Montgomery, S. B., Dupre, Y., et al. (2011). DNA methylation profiles of human active and inactive $\mathrm{X}$ chromosomes. Genome Res, 21(10), 1592-1600.

Shemer, R., Birger, Y., Dean, W. L., Reik, W., Riggs, A. D., \& Razin, A. (1996). Dynamic methylation adjustment and counting as part of imprinting mechanisms. Proc Natl Acad Sci U S A, 93(13), 6371-6376.

Shen, H., \& Laird, P. W. (2012). In epigenetic therapy, less is more. Cell Stem Cell, 10(4), 353354.

Shen, H., \& Laird, P. W. (2013). Interplay between the cancer genome and epigenome. Cell, 153(1), 38-55.

Shen, Y., Aoyagi-Scharber, M., \& Wang, B. (2015). Trapping Poly(ADP-Ribose) Polymerase. $J$ Pharmacol Exp Ther, 353(3), 446-457.

Siebenkas, C., Chiappinelli, K. B., Guzzetta, A. A., Sharma, A., Jeschke, J., Vatapalli, R., et al. (2017). Inhibiting DNA methylation activates cancer testis antigens and expression of the antigen processing and presentation machinery in colon and ovarian cancer cells. PLoS One, 12(6), e0179501.

Silverman, L. R., Demakos, E. P., Peterson, B. L., Kornblith, A. B., Holland, J. C., OdchimarReissig, R., et al. (2002). Randomized controlled trial of azacitidine in patients with the myelodysplastic syndrome: a study of the cancer and leukemia group B. J Clin Oncol, 20(10), 2429-2440.

Simmer, F., Brinkman, A. B., Assenov, Y., Matarese, F., Kaan, A., Sabatino, L., et al. (2012). Comparative genome-wide DNA methylation analysis of colorectal tumor and matched normal tissues. Epigenetics, 7(12), 1355-1367.

Smallwood, S. A., Tomizawa, S., Krueger, F., Ruf, N., Carli, N., Segonds-Pichon, A., et al. (2011). Dynamic CpG island methylation landscape in oocytes and preimplantation embryos. Nat Genet, 43(8), 811-814.

Smith, J. R., \& Pereira-Smith, O. M. (1996). Replicative senescence: implications for in vivo aging and tumor suppression. Science, 273(5271), 63-67.

Smith, Z. D., \& Meissner, A. (2013). DNA methylation: roles in mammalian development. Nat Rev Genet, 14(3), 204-220.

Steensma, D. P., Baer, M. R., Slack, J. L., Buckstein, R., Godley, L. A., Garcia-Manero, G., et al. (2009). Multicenter study of decitabine administered daily for 5 days every 4 weeks to 
adults with myelodysplastic syndromes: the alternative dosing for outpatient treatment (ADOPT) trial. J Clin Oncol, 27(23), 3842-3848.

Suetake, I., Shinozaki, F., Miyagawa, J., Takeshima, H., \& Tajima, S. (2004). DNMT3L stimulates the DNA methylation activity of Dnmt3a and Dnmt3b through a direct interaction. J Biol Chem, 279(26), 27816-27823.

Sui, H., Ma, N., Wang, Y., Li, H., Liu, X., Su, Y., et al. (2018). Anti-PD-1/PD-L1 Therapy for Non-Small-Cell Lung Cancer: Toward Personalized Medicine and Combination Strategies. J Immunol Res, 2018, 6984948.

Tahiliani, M., Koh, K. P., Shen, Y., Pastor, W. A., Bandukwala, H., Brudno, Y., et al. (2009). Conversion of 5-methylcytosine to 5-hydroxymethylcytosine in mammalian DNA by MLL partner TET1. Science, 324(5929), 930-935.

Takebayashi, S., Tamura, T., Matsuoka, C., \& Okano, M. (2007). Major and essential role for the DNA methylation mark in mouse embryogenesis and stable association of DNMT1 with newly replicated regions. Mol Cell Biol, 27(23), 8243-8258.

Thienpont, B., Steinbacher, J., Zhao, H., D'Anna, F., Kuchnio, A., Ploumakis, A., et al. (2016). Tumour hypoxia causes DNA hypermethylation by reducing TET activity. Nature, 537(7618), 63-68.

Thottassery, J. V., Sambandam, V., Allan, P. W., Maddry, J. A., Maxuitenko, Y. Y., Tiwari, K., et al. (2014). Novel DNA methyltransferase-1 (DNMT1) depleting anticancer nucleosides, 4'-thio-2'-deoxycytidine and 5-aza-4'-thio-2'-deoxycytidine. Cancer Chemother Pharmacol, 74(2), 291-302.

Timp, W., \& Feinberg, A. P. (2013). Cancer as a dysregulated epigenome allowing cellular growth advantage at the expense of the host. Nat Rev Cancer, 13(7), 497-510.

van Dongen, J., Nivard, M. G., Willemsen, G., Hottenga, J. J., Helmer, Q., Dolan, C. V., et al. (2016). Genetic and environmental influences interact with age and sex in shaping the human methylome. Nat Commun, 7, 11115.

van Groeningen, C. J., Leyva, A., O'Brien, A. M., Gall, H. E., \& Pinedo, H. M. (1986). Phase I and pharmacokinetic study of 5-aza-2'-deoxycytidine (NSC 127716) in cancer patients. Cancer Res, 46(9), 4831-4836.

Vardiman, J. W., Harris, N. L., \& Brunning, R. D. (2002). The World Health Organization (WHO) classification of the myeloid neoplasms. Blood, 100(7), 2292-2302.

Viner, C., Johnson, J., Walker, N., Shi, H., Sjöberg, M., Adams, D. J., et al. (2016). Modeling methyl-sensitive transcription factor motifs with an expanded epigenetic alphabet. bioRxiv, 043794.

Von Hoff, D. D., Schilsky, R., Reichert, C. M., Reddick, R. L., Rozencweig, M., Young, R. C., et al. (1979). Toxic effects of cis-dichlorodiammineplatinum(II) in man. Cancer Treat Rep, 63(9-10), 1527-1531.

Wahlfors, J., Hiltunen, H., Heinonen, K., Hamalainen, E., Alhonen, L., \& Janne, J. (1992). Genomic hypomethylation in human chronic lymphocytic leukemia. Blood, 80(8), 20742080.

Wajed, S. A., Laird, P. W., \& DeMeester, T. R. (2001). DNA methylation: an alternative pathway to cancer. Ann Surg, 234(1), 10-20.

Walsh, C. P., Chaillet, J. R., \& Bestor, T. H. (1998). Transcription of IAP endogenous retroviruses is constrained by cytosine methylation. Nat Genet, 20(2), 116-117. 
Wang, J., Hevi, S., Kurash, J. K., Lei, H., Gay, F., Bajko, J., et al. (2009). The lysine demethylase LSD1 (KDM1) is required for maintenance of global DNA methylation. Nat Genet, 41(1), 125-129.

Weber, J. S., D'Angelo, S. P., Minor, D., Hodi, F. S., Gutzmer, R., Neyns, B., et al. (2015). Nivolumab versus chemotherapy in patients with advanced melanoma who progressed after anti-CTLA-4 treatment (CheckMate 037): a randomised, controlled, open-label, phase 3 trial. Lancet Oncol, 16(4), 375-384.

Weisenberger, D. J., Campan, M., Long, T. I., Kim, M., Woods, C., Fiala, E., et al. (2005). Analysis of repetitive element DNA methylation by MethyLight. Nucleic Acids Res, $33(21), 6823-6836$.

Wherry, E. J. (2011). T cell exhaustion. Nat Immunol, 12(6), 492-499.

Widschwendter, M., Jiang, G., Woods, C., Muller, H. M., Fiegl, H., Goebel, G., et al. (2004). DNA hypomethylation and ovarian cancer biology. Cancer Res, 64(13), 4472-4480.

Wu, H., D'Alessio, A. C., Ito, S., Xia, K., Wang, Z., Cui, K., et al. (2011). Dual functions of Tet1 in transcriptional regulation in mouse embryonic stem cells. Nature, 473(7347), 389-393.

Wu, S. C., \& Zhang, Y. (2010). Active DNA demethylation: many roads lead to Rome. Nat Rev Mol Cell Biol, 11(9), 607-620.

Xiao, M., Yang, H., Xu, W., Ma, S., Lin, H., Zhu, H., et al. (2012). Inhibition of alpha-KGdependent histone and DNA demethylases by fumarate and succinate that are accumulated in mutations of FH and SDH tumor suppressors. Genes Dev, 26(12), 13261338.

Xu, W., Yang, H., Liu, Y., Yang, Y., Wang, P., Kim, S. H., et al. (2011). Oncometabolite 2hydroxyglutarate is a competitive inhibitor of alpha-ketoglutarate-dependent dioxygenases. Cancer Cell, 19(1), 17-30.

Yang, X., Han, H., De Carvalho, D. D., Lay, F. D., Jones, P. A., \& Liang, G. (2014). Gene body methylation can alter gene expression and is a therapeutic target in cancer. Cancer Cell, 26(4), 577-590.

Yin, Y., Morgunova, E., Jolma, A., Kaasinen, E., Sahu, B., Khund-Sayeed, S., et al. (2017). Impact of cytosine methylation on DNA binding specificities of human transcription factors. Science, 356(6337). 